\title{
InAs/InP quantum-dash lasers
}

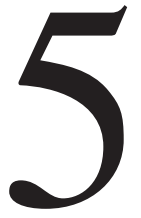

\author{
M.Z.M. Khan ${ }^{\mathrm{a}}$, E.A. Alkhazraji ${ }^{\mathrm{a}}$, M.T.A. Khan ${ }^{\mathrm{a}}$, T.K. $\mathbf{N g}^{\mathrm{b}}$, B.S. $\mathbf{0} \mathrm{oi}^{\mathrm{b}}$ \\ ${ }^{a}$ Optoelectronics Research Laboratory, Electrical Engineering Department, King Fahd University \\ of Petroleum \& Minerals, Dhahran, Saudi Arabia; ${ }^{b}$ Photonics Laboratory, Computer, Electrical \\ and Mathematical Sciences and Engineering (CEMSE) division, King Abdullah University of \\ Science \& Technology (KAUST), Thuwal, Saudi Arabia
}

\section{Introduction}

With the advent of the optical fiber technology, the ever-increasing demand for wide bandwidth reliable solutions to satiate the today's world's thirst for in the $1.55 \mu \mathrm{m}$ C-band optical communication window has driven analysis and research for high performance active optical devices including light-emitting diodes, semiconductor lasers, semiconductor optical amplifiers (SOA), mode-locked lasers, and modulators. Quantum confined nanostructure based active-regions in the form of quantum-wells (Qwells) and self-assembled quantum-dots (Qdots) have been garnering the focus of research in the past couple of decades as prime contenders for the sought highly efficient compact semiconductor devices and optical sources owning to the high quality epitaxial growth on GaAs substrates emitting at $\sim 1.3 \mu \mathrm{m}$ and being commercialized with excellent performance parameters. Nevertheless, their inability to reach the C-band window of $1.55 \mu \mathrm{m}$ and beyond resulted in InP substrate-grown devices to take spot light of research and to commercially dominate over their GaAs counterparts [1,2].

However, a new class of self-assembled nanostructures, dubbed as quantum dash, has emerged as elongated quantum wire-like structures resulting from the small lattice mismatch during self-assembly growth of Qdots. These Qdashes exhibit peculiar characteristics in-between Qwell and Qdots and have shown to exhibit a wide tuning range of emission from $\sim 1.5 \mu \mathrm{m}$ and all the way up to $\sim 2.0 \mu \mathrm{m}$ and beyond [3-5]. These InAs nanostructures on both InGaAlAs and InGaAsP material systems alike have witnessed wide strides in research and development while displaying decent performance parameters. Nevertheless, the inherent inhomogeneous nature of these structures in the form of their shape and size dispersion as a result of the self-assembled growth process itself poses and obstacle in realizing high quality epitaxial material and, thus the results laser device performance.

With that said, the very inhomogeneous nature of InAs/InP Qdashes can be rather exploited for their ultra-broad gain profiles and utilized as broadband laser components with coverage bandwidths exceeding $50 \mathrm{~nm}$ [6]. Furthermore, with passive 
mode-locking, ultra-short femto-second pulse trains can be generated which can be crucial in applications including wavelength-division multiplexed (WDM) optical communication systems and high-speed optical time-domain multiplexers (OTDMs). Moreover, the remarkable tunability that has been shown by these structures covering the entire $\mathrm{C}-, \mathrm{L}-$, and $\mathrm{U}-$ optical communication bands and even exceeding $2 \mu \mathrm{m}$, in addition to the aforementioned ultra-broad gain profiles can be invaluable to serve multi-disciplinary applications. In medical applications, for once, InAs/InP Qdash based lasers offer low cost compact solution with a high tunability and axial resolution to potentially replace bulk and solid state lasers in medical diagnosis, optical coherent tomography, bio-molecular and tissue imaging, and high-precision surgery and dentistry [7-11]. Nonetheless, in molecular and material sensing and characterization, these devices can be utilized as portable broad long wavelength sources in applications such as light detection and ranging (LIDAR), chemical sensing, in-situ multicomponent analysis, and spectroscopy. Furthermore, the exceptionally broad spectra of such optical laser sources can be very beneficial to some fields such as non-destructive testing, material research, imaging ceramics, birefringence imaging of crystalline polymer structures and studying their penetration depths [12].

In this chapter, we discuss the existing self-assembled growth of InAs Qdash based nanostructures on (100) and (311) B InP substrates for eventual operation in the $\mathrm{C}-\mathrm{L}-\mathrm{U}$ band and toward $2 \mu \mathrm{m}$. The tremendous progress in this area resulted in an astounding amount of literature. Section 2 of this chapter discusses the achievements in the epitaxial material growth of InAs/InP quantum dash material systems. Subsequently, Section 3 discusses the device-level employment of these structures as semiconductor laser sources in addition to the respective utilization of optical injection (injection locking) and mode-locking in their employment. Finally, Section 4 concludes this chapter by discussing the recent employment of Qdash lasers as promising sources for future optical communication systems.

\section{Growth of InAs/InP quantum dash lasers}

The phrase "Quantum dash" was introduced at the end of the last century with the first introduction of self-assembled InAs Qdashes grown over (211)B GaAs substrates by Guo et al. [12] and InSb Qdashes over (100) InP substrates by Utzmeier et al. [13]. However, only at the beginning of this millennium is when they properly began being employed and identified in actual optoelectronic applications. Qdash laser structures were dominated by two material systems: (i) InAs/InGaAlAs and (ii) InAs/InGaAsP.

\subsection{InAs/InGaAIAs material system}

In 1999, via Molecular Beam Epitaxy (MBE), Li et al. [14] introduced a 6-stack of high density $\left(\sim 70 \mu \mathrm{m}^{-1}\right)$ InAs/ $\mathrm{Al}_{0.48} \mathrm{In}_{0.52} \mathrm{As}$ quantum-wire like nanostructures, on 
a (100) InP substrate with InAlAs buffer layers. The structure displayed a photoluminescence (PL) peak at $1.9 \mu \mathrm{m}$ in addition to a large anisotropy that was scribed to results in the reported high density. Later on, through TEM analysis, they concluded that increasing the deposition of InAs from 1.5 to 7.5 monolayer (ML) resulted in increasing the inhomogeneity and the sizes of the formed Qdashes [15].

The first report of dash-in-well (DaWELL) structure was by Wang et al. [3] who demonstrated the growth of InAs Qdashes with a density of $\sim 10^{10} \mathrm{~cm}^{-2}$ within an asymmetric InGaAlAs Qwell layer separated by strained barrier layers of InGaAlAs that exhibited a PL peak at $\sim 1.57 \mu \mathrm{m}$. To follow up, a parametric study was carried out by Schwertberger et al. [16] on different MBE Qdash InAs growth parameters. It was observed that at a fixed substrate temperature, increasing the thickness of the deposited InAs from 2.5 to $7 \mathrm{ML}$ had dramatically increased the height and decreased the length of the Qdashes. Fig. 5.1A shows the PL spectra at different nominal InAs layer thickness covering the emission band from $\sim 1.2$ to $\sim 2.0 \mu \mathrm{m}$. Nevertheless, more deposition thickness was found to lead the Qdashes to coalesce into islands of greater size with a reduction in the dash nature of the structure. Moreover, the substrate growth temperature was investigated after which they suggested an optimal value of $\sim 500{ }^{\circ} \mathrm{C}$ that was observed to result in a maximum PL intensity.

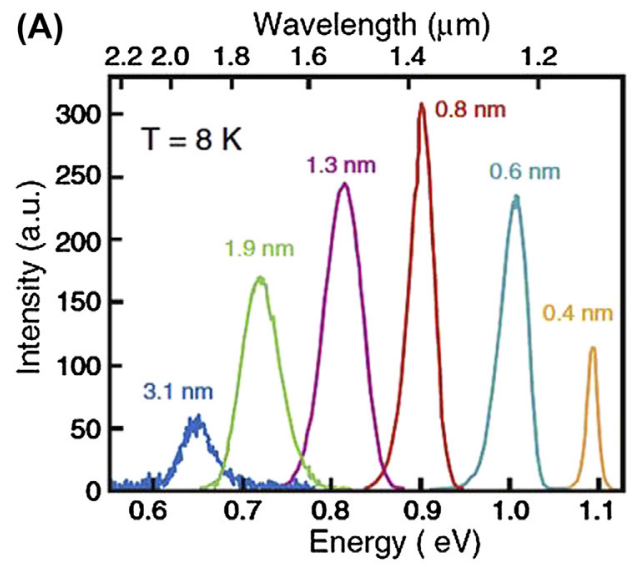

(B)

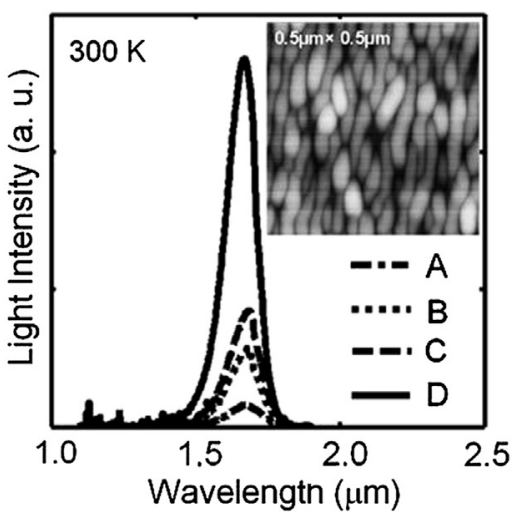

FIG. 5.1

(A) Low temperature PL spectra of Qdash layers with different nominal InAs layer thickness as indicated in the figure, on InGaAlAs buffer layer on (100) InP substrate [16].

(B) PL spectra measured at $300 \mathrm{~K}$ for four InAs Qdash samples grown at various conditions ( $A$ and $B$ with InGaAlAs barrier grown at $505^{\circ} \mathrm{C}$ and $535^{\circ} \mathrm{C}$, respectively. $\mathrm{C}$ and $D$ are similar to $B$ except an ultra-thin GaAs layer was grown before the growth of InAs layer, and before and after the growth of InAs layer, respectively). Inset shows the $\left(0.5 \times 0.5 \mu \mathrm{m}^{2}\right)$ AFM image of an InAs Qdash layer without InAIGaAs cap [19].

From Khan MZM, Ng TK, Ooi BS. Self-assembled InAs/InP quantum dots and quantum dashes: material structures and devices. Progress in Quantum Electronics 2014;38(6):237-313. 
Rotter et al. reported another striking tunability of DaWELL structure [17] as then demonstrated a PL peak emission shift between 1.52 and $2.04 \mu \mathrm{m}$. Later, Sauerwald et al. [18] showed that the emission of a single stack of Qdash can be tuned in the range of 1.39-1.90 $\mu \mathrm{m}$ undependably of the composition and the shape of the Qdashes by adjusting the thickness of InAs deposition which they demonstrated to have a linear relationship with the size of the grown Qdashes leading to red shifting the PL peak in addition to broadening its linewidth. Moreover, they extended the investigation [19] to cover multistacks of InAs/InGaAlAs DaWELL structures to analyze the effect of more Qdash layer stacking which was shown to increase the size of the grown Qdashes. This was attributed to the extra strain effects in the upper layers that resulted in the merging of the grown dashes at different rates which ultimately results in more inhomogeneity in the DaWELL structure.

Later, Mi et al. [20] demonstrated the possibility of achieving a significantly better optical performance by growing ultrathin layers $(\sim 2 \mathrm{ML})$ of GaAs over the InGaAlAs barrier prior to deposing InAs. As such, they reported more than 3 times higher PL intensity as depicted in Fig. 5.1B while a more drastic enhancement $(>10$ times) in the PL intensity along with a reduced linewidth $(\sim 50 \mathrm{meV})$ is achieved when more GaAs layers are deposited after the growth of the capping layer which all was accredited to the suppressed phase separation and enhanced surface migration in the barrier layer. In 2008, Podemski et al. [21] reported a highly stacked columnar Qdashes over (100) InP that are sandwiched between InGaAlAs layers and within buffer layers of InAlAs. They demonstrated that the dominant polarization could be transitioned from transverse electric to transverse magnetic via controlling the number of stacking layers from 1 to 24 in addition to red shifting the PL peak, as shown in Fig. 5.1D due to the larger sizes of the grown Qdashes.

\subsection{InAs/InGaAsP material system}

González et al. [22] demonstrated the significance of the buffer layer in forming InAs nanostructures by growing buffer layer of InP using atomic-layer MBE that yielded in self-assembled quantum wire-like structures that are elongated in the [1-10] direction. Then, it was postulated that anisotropic stress relaxation of the heteroepitaxial system involving different group V elements was responsible in the formation of these Qwires [23]. Later, Gendry et al. showed [24] that increasing the growth temperature results in lowering the critical thickness of the growth mode transition of a single stack of quantum-sticks within a matrix layer of InP. This in turn, leads to reducing the height dispersion of the grown dashes making for a more uniform grown island as illustrated in Fig. 5.2A. Furthermore, it was found that few growth parameters can be optimized to reduce the height dispersion including reducing the Arsenic overpressure during InAs deposition (as shown in Fig. 5.2B), increasing the InAs thickness drastically, and higher growth temperature. This was attributed to the thermodynamics and kinetics such as adatom surface diffusion and strain accumulation which improved the self-organization of the grown islands [24]. Building upon that work, Fuster et al. [25] investigated the effect 
(A)

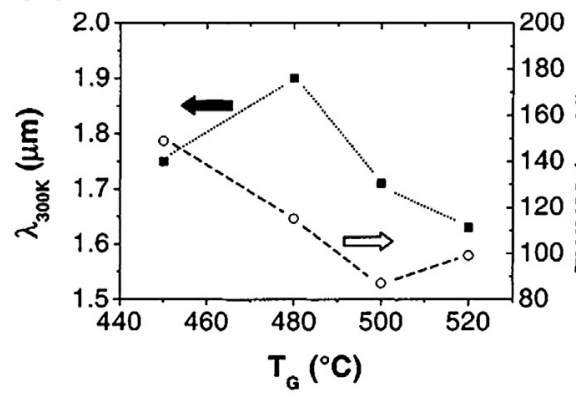

(B)

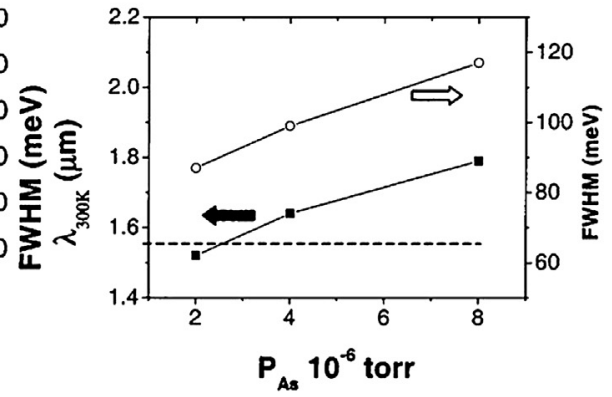

FIG. 5.2

(A) PL characteristics [peak emission and linewidth] of InAs island's PL spectra on InP buffer layer at $300 \mathrm{~K}$ as a function of the growth temperature for an InAs deposition thickness just above ( $\sim 0.5 \mathrm{ML}$ ) the critical thickness. (B) PL characteristics of InAs islands on $\mathrm{InP}$ at $300 \mathrm{~K}$ versus the As overpressure during the InAs growth (growth temperature $520^{\circ} \mathrm{C}$, InAs deposition thickness $0.9 \mathrm{~nm}$ ) [24].

From Khan MZM, Ng TK, Ooi BS. Self-assembled InAs/InP quantum dots and quantum dashes: material structures and devices. Progress in Quantum Electronics 2014;38(6):237-313.

of thickness of the InAs layer which was found to have a proportional relationship with the size of the formed Qwires, as illustrated in Fig. 5.3A, which lies in line with the other reports on the InAs/InGaAlAs material system.

Subsequently, Alen et al. [26] showed that structures of thinner InP spacer layers were associated with a higher degree of homogeneity by comparing two specimens of 10-stack InAs/InP Qwires grown over spacer layers of 5 and $10 \mathrm{~nm}$. This uniformity was accredited to the strain driven vertical filtering of the size of the grown Qwires along growth direction. On the other hand, thicker spacer layers resulted in high inhomogeneity with a broad PL linewidth of $\sim 350 \mathrm{meV}$ which agrees with Podemski et al. [21] work on the InAs/InGaAlAs material system. Later, Lelarge et al. empirically utilized [27] growth conditions, number of layers Qdashes, their thickness, and the strain of the barrier layers as parameters in order to identify the nominal thickness of subsequent layers that compensated for any thickening of the Qdashes during growth which ultimately enabled achieving homogeneity in the sizes of the Qdashes without ultrathin barrier layers. As such, they demonstrated up to 10 stacks with a barrier layer thickness of $40 \mathrm{~nm}$ with a minimal impact on the PL linewidth as it was kept around $\sim 70 \mathrm{meV}$, as shown in Fig. 5.3B. Keeping up with the same purpose, Faugeron et al. [28] introduced an alternative methodology. They adopted an asymmetrical cladding technique by inserting an undoped index slab layer between the Qdash active region and the substrate. This introduction resulted in a reduced overlap among the optical modes which maintained the PL linewidth and optical quality of the 6 -stach structure whose PL peak at $\sim 1.57 \mu \mathrm{m}$.

On other front, several works have been carried to increase the Qdash structure inhomogeneity. Although, this inherently demerits the optical performance of Qdash 
(A)

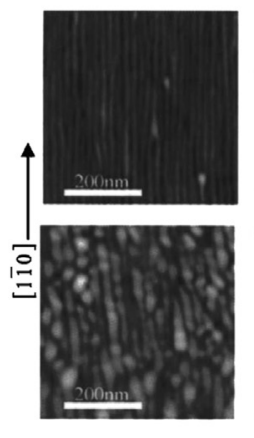

(B)

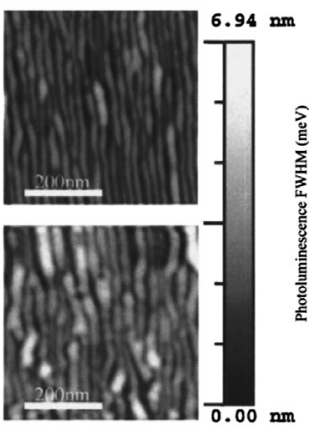

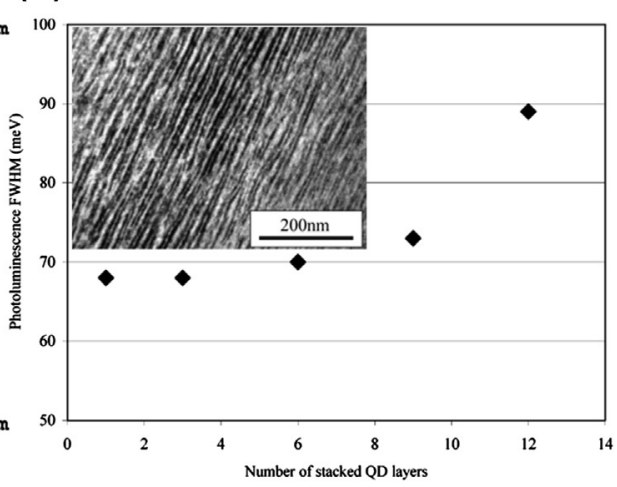

FIG. 5.3

(A) AFM images $\left(0.5 \times 0.5 \mu \mathrm{m}^{2}\right)$ of four uncapped InAs Qwire samples with different InAs deposited thicknesses 2.5 ML, 3.3 ML, 4.3 ML, and 5.3 ML from upper left to bottom right. The four images have the same z-scale bar [25]. (B) Room temperature PL linewidth of stacked InAs/InGaAsP Qdashes as a function of the number of stacking layers. Inset shows the plan-view TEM micrograph of a stack of 6 Qdash layers [27].

From Khan MZM, Ng TK, Ooi BS. Self-assembled InAs/InP quantum dots and quantum dashes: material structures and devices. Progress in Quantum Electronics 2014;38(6):237-313.

lasers due to the trade-off between the spectral linewidth and threshold gain, in some applications such as WDM based communications and realization of semiconductor optical amplifier (SOA), the need for the inhomogeneous broadening warrants said trade-off. With that goal in sight, Deubert et al. [29] introduced a chirping technique where the InAs nominal thicknesses a 6-stack Qdash structure was varied between 3 and 4.6 ML at a fixed barrier thickness of $25 \mathrm{~nm}$. This yielded in a broad PL that was $\sim 45 \%$ higher to the traditional 4-stack structure with a fixed InAs layer thickness. Soon after, Reithmaier et al. [30] reported a large gain-bandwidth of $270 \mathrm{~nm}$ with peak gain of $40 \mathrm{~cm}^{-1}$ using a similar chirped design of 4 varying InAs layers at a fixed barrier layer. Based on the analytical results of the thickness of the barrier layer on the inhomogeneity of the structure [31], our group demonstrated [32] an ultrabroad PL linewidth of $\sim 151 \mathrm{~nm}$ by utilizing a chirped 4-stack InGaAlAs DaWELL structure with varying barrier layers $(20,15,10,10 \mathrm{~nm})$ that was drastically broader than a similar structure of a fixed barrier layer thickness $(10 \mathrm{~nm})$ among the different layers where the PL linewidth was $\sim 100 \mathrm{~nm}$. Under continuous wave $(\mathrm{CW})$ current density of $8.3 \mathrm{kA} / \mathrm{cm}^{2}$, the gain-bandwidth was measured [33] as $\sim 140 \mathrm{~nm}$ with a peak modal gain of $\sim 41 \mathrm{~cm}^{-1}$ as shown in Fig. 5.4A.

Very recently, Pes et al. utilized Gas Source MBE in growing a 6-stack InAs Qdashes of 3 sets on a (001) InP substrate [34]. Each Qdash layer was separated by a $\mathrm{In}_{0.8} \mathrm{Ga}_{0.2} \mathrm{As}_{0.435} \mathrm{P}$ barrier layer of a thickness of $15-\mathrm{nm}$ and surrounded by quaternary alloy layers whose thickness was chosen to ensure a homogenous excitation 
(A)

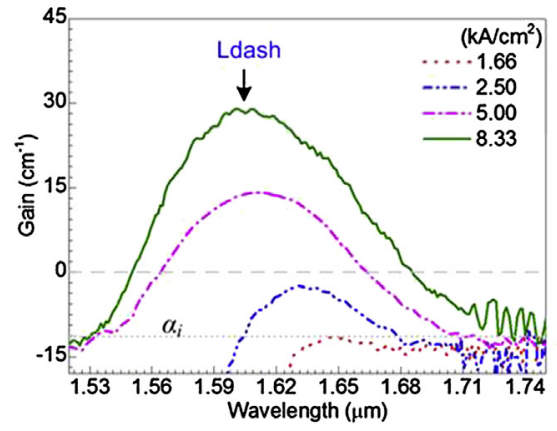

(B)

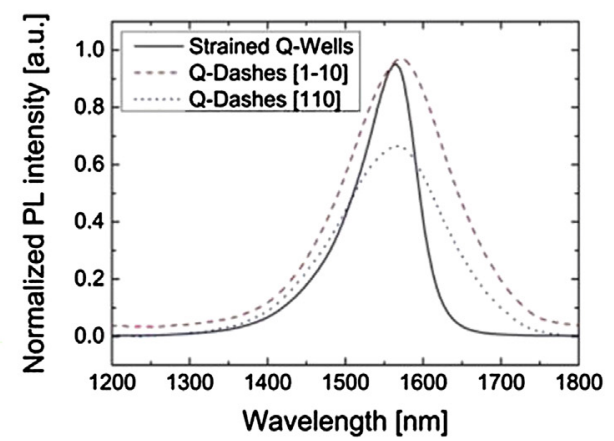

FIG. 5.4

(A) Gain of a four stack DaWELL InAs/InGaAIAs/InP laser structure with chirped barrier layer thickness (10, 10, 15, $20 \mathrm{~nm}$ ) [33]. (B) PL spectra of two specimens of 6-stack InAs Qdashes along two different directions compared to a strained quantum-well structure.

From Khan MZM, Ng TK, Ooi BS. Self-assembled InAs/InP quantum dots and quantum dashes: material structures and devices. Progress in Quantum Electronics 2014;38(6):237-313. Also reprinted with permission from Pes $S$, et al. Class-A operation of an optically-pumped $1.6 \mu \mathrm{m}$-emitting quantum dash-based verticalexternal-cavity surface-emitting laser on InP. Optical Express 2017;25(10):11760-6.

of the active region. The PL of two Qdash specimens elongated along the [1-10] and [110] directions, as shown in Fig. 5.4B, showed a very broad linewidth while keeping the integrated PL intensity comparable to that of a 6-stack strained quantum-well structure, thus providing more insight to Qdash active region physics.

\section{InAs/InP Qdash lasers}

In this section, we discuss Qdash active regions in edge-emitting Fabry-Perot lasers, injection-locked lasers, and mode-locked lasers. Owning to the inhomogeneous nature of their structure, the stimulated emission of Qdash lasers is associated with broad spectral linewidth as has been discussed earlier. In addition, the resulted sub-picosecond pulses with mode locking has the potential to improve the performance dramatically.

\subsection{InAs/InGaAIAs/InP Qdash lasers}

Wang et al. were first to demonstrate a semiconductor Qdash [3] active region based laser that consisted of 1-, 3-, and 5-stack InAs/InGaAlAs DaWELL and emitting at $1.60,1.62$, and $1.66 \mu \mathrm{m}$, respectively. Fig. 5.5A shows the L-I characteristics while the electroluminescence spectrum is shown in its inset. The devices were 1.5-4.0 mm long broad-area lasers with threshold current densities of 410, 167, and $766 \mathrm{~A} / \mathrm{cm}^{2}$ per layer, respectively, while the internal loss and internal quantum 

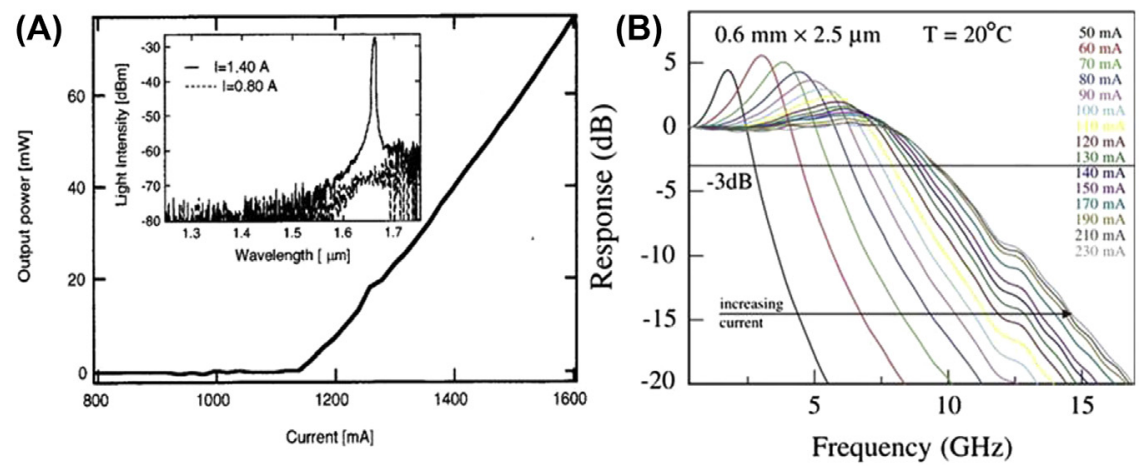

FIG. 5.5

(A) A two-facet light output versus pulsed injection current measured on a five-stack Qdash laser diode with geometry of $100 \times 1500 \mu \mathrm{m}^{2}$ [3]. The inset in (A) is the electroluminescence spectra under different pump levels for the device [38]. (B) Room temperature small-signal modulation response of a ridge-waveguide $2.5 \times 600 \mu \mathrm{m}^{2}$ undoped InAs/InGaAIAs Qdash laser for various CW drive currents [42].

From Khan MZM, Ng TK, Ooi BS. Self-assembled InAs/InP quantum dots and quantum dashes: material structures and devices. Progress in Quantum Electronics 2014;38(6):237-313.

efficiency were $\sim 10 \mathrm{~cm}^{-1}$ and $\sim 60 \%$, respectively. These promising results in addition to the $\sim 15 \mathrm{~cm}^{-1}$ acquired modal gain, were bound to motivate and push research and further investigation on this particular system. As such, Schwertberger et al. [35] later demonstrated the tunability of InAs/InGaAlAs Qdash lasers in the range of $1.54-1.78 \mu \mathrm{m}$ by tuning the thickness of InAs deposition layer between 5.0 and 7.5 ML. A low threshold current density of $225 \mathrm{~A} / \mathrm{cm}^{2}$ per layer off a 4-stack $40 \times 1000 \mu \mathrm{m}^{2}$ device was reported, with total output power exceeding $100 \mathrm{~mW}$ and a characteristic temperature $\mathrm{T}_{0}$ of $\sim 61 \mathrm{~K}$. Later on, with an improved material quality evident by the $60 \%$ quantum efficiency and $8.5 \mathrm{~cm}^{-1}$ internal loss [16], the transparency current density was further reduced to as low as $90 \mathrm{~A} / \mathrm{cm}^{2}$ per layer which is one of the best values reported on this material system. On the same venue, Rotter et al. [17] were able to push the emission wavelength to as long as $2.03 \mu \mathrm{m}$ which is the longest emission wavelength reported on any InAs/InP Qdash laser structure. This was carried out on a 5-stack InAs DaWELL structure over a (100) InP substrate with a 52\% internal quantum efficiency and a per-layer threshold current density of $108 \mathrm{~A} / \mathrm{cm}^{2}$. However, the significantly high internal loss of $\sim 55 \mathrm{~cm}^{-1}$ was attributed to Rayleigh scattering that was caused by the refractive index local undulations in the vicinity of the Qdashes.

Subsequently, Resneau et al. [36] demonstrated a flat low relative intensity noise (RIN) of $-162 \mathrm{~dB} / \mathrm{Hz}$ and a total power $>100 \mathrm{~mW}$ on a 4 stack graded separate confinement heterostructure $(\mathrm{SCH}) \mathrm{InAs} / \mathrm{InGaAlAs}$ ridge-waveguide Qdash laser emitting at $1.57 \mu \mathrm{m}$. Furthermore, the corresponding internal loss was very low $4 \mathrm{~cm}^{-1}$ which is among the lowest on this material system. Furthermore, through 
the dynamic characteristics measurements, the acquired modulation efficiency and maximum intrinsic bandwidth were of $0.36 \mathrm{GHz} / \mathrm{mA}^{0.5}$ and $5.9 \mathrm{GHz}$, respectively, while the $\mathrm{K}$-factor was $1.51 \mathrm{~ns}$. Later on, the modulation efficiency and resonance frequency were pushed to $0.72 \mathrm{GHz} / \mathrm{mA}^{0.5}$ and $7.5 \mathrm{GHz}$, respectively [37]. On another front, Mi et al. [20] demonstrated the largest small signal modulation bandwidth (up to $12 \mathrm{GHz}$ ) in an InAs/InP Qdash system at any temperature $\left({ }^{\circ} \mathrm{C}\right.$ ) with a reduced sub-threshold linewidth-enhancement factor (LEF) $<0.7$ and a high characteristic temperature $\mathrm{T}_{0}$ of $\sim 204 \mathrm{~K}$. This was attributed to the minimized carrier leakage and hot carrier effects by the virtue of the p-doping and tunnel injection that were implemented simultaneously. Nevertheless, the best small signal modulation bandwidth in a Qdash system at room temperature was $9.6 \mathrm{GHz}$ that was reported by Hein et al. [38] who employed a $2.5 \times 600 \mu \mathrm{m}^{2}$ undoped 6-stack InAs/ InGaAlAs Qdash laser under CW operation. The obtained modulation efficiency was $0.82 \mathrm{GHz} / \mathrm{mA}^{0.5}$ while the $\mathrm{K}$-factor and maximum intrinsic bandwidth were $0.78 \mathrm{~ns}$ and $11.4 \mathrm{GHz}$, respectively as depicted in Fig. 5.5B. Moreover, the abovethreshold LEF was acquired as 2.5 via the amplitude-modulation/frequencymodulation method. In terms of the threshold current density, Hein et al. [39] reported the best value in any multi-stack Qdash $\left(46 \mathrm{~A} / \mathrm{cm}^{2}\right.$ per layer) system and on a 16-stack 1.3-mm long columnar Qdash laser structure that lased at $1.7 \mu \mathrm{m}$, followed by $108 \mathrm{~A} / \mathrm{cm}^{2}$ per layer threshold current density value reported by Rotter et al. [17]. On the other hand, the $93 \%$ internal quantum efficiency of the 4-stack Qdash laser that was reported by our group [40] is the highest in a Qdash laser. Furthermore, our group also demonstrated the enhancement in the performance of the Qdash laser lasing at $\sim 1.61 \mu \mathrm{m}$ in the form of a $\sim 45 \%$ and $\sim 11 \%$ reduction in the transparency current density and threshold current, respectively without compromising the other laser performance parameters via controlling the IFVD intermixing process.

Very recently, Rudno-Rudziński et al. [41] investigated the influence of the width of the quantum well layer on the injection-tunneling of Qdash based material system. The InAs Qdashes were separated from the InGaAs quantum-well layer by a 2.3-nm thick barrier layer. The coupling affects both spectral and temporal optical response by altering the isolated $\mathrm{OD}$ character of the ground state emission for wide quantum wells. In such cases, it was suggested that the ground state emission becomes indirect, as evident by the elongation of the PL decay time from 2 ns to $10 \mathrm{~ns}$.

\subsection{InAs/InGaAsP/InP Qdash lasers}

This material system was adopted relatively later in Qdash lasers starting with Moreau et al.'s [42] report on the effects of p-doping and multi-stacking on the performance of a 9-stack InAs/InGaAsP DaWELL laser on (100) InP substrate emitting at $1.52 \mu \mathrm{m}$. A low threshold current density of $123 \mathrm{~A} / \mathrm{cm}^{2}$ per layer was obtained from the $50 \times 600 \mu \mathrm{m}^{2}$ device at room temperature. In addition, the transparency current density was found as $83 \mathrm{~A} / \mathrm{cm}^{2}$ per layer while the modal gain was $5.4 \mathrm{~cm}^{-1}$ per 
layer. The results were found to be superior when in comparison with the performance of a 6-stack and 12-stack Qdash lasers.

In a different report, Lelarge et al. [27] demonstrated a significant improvement in the transparency current density of a $50 \times 2000 \mu \mathrm{m}^{2}$ DaWELL laser $\left[660 \mathrm{~A} / \mathrm{cm}^{2}\right.$ $\left(110 \mathrm{~A} / \mathrm{cm}^{2}\right.$ per layer)] when compared with a similar Qdash-in-barrier based laser $\left[1140 \mathrm{~A} / \mathrm{cm}^{2}\right.$ (190 A/ $\mathrm{cm}^{2}$ per layer)], likely due to the better carrier injection [43] in the case of the former scheme, as shown in Fig. 5.6A. Moreover, this was accompanied by redshift in the emission from 1.56 to $1.65 \mu \mathrm{m}$ in the former and latter schemes, respectively. The internal loss and internal quantum efficiency were obtained as $19 \mathrm{~cm}^{-1}$ and $80 \%$ while the modal gain was high $105 \mathrm{~cm}^{-1}$. It was also pointed out that despite of the p-doping, the characteristic temperature $\mathrm{T}_{0} \sim 60 \mathrm{~K}$ did not exhibit a significant increase possibly due to either the band structure or the shape of the nanostructures. Nevertheless, by employing buried ridge fabrication in addition to the high-quality optimization of the growth process of Qdash, the characteristic temperature was able to be pushed to as high as $\mathrm{T}_{0} \sim 135 \mathrm{~K}$ on a p-doped 6-stack Qdash-in-barrier laser with twice as high modal gain $\left(11 \mathrm{~cm}^{-1}\right.$ per layer $)$ with respect to the undoped laser at the expense of a high threshold current density $\sim 10 \mathrm{kA} / \mathrm{cm}^{2}$ and internal loss $\left(\sim 60 \mathrm{~cm}^{-1}\right)$ [44]. Furthermore, a drastic improvement in the device dynamic characteristics was witnessed as the relaxation frequency was a high $13.5 \mathrm{GHz}$ which was acquired through RIN measurements $(-155$ to $-160 \mathrm{~dB} / \mathrm{Hz}$ from 0.5 to $20 \mathrm{GHz})$ and is among the best reported values in an InAs/InP Qdash material system. Dagens et al. [45] were able to further optimize the design of the Qdash active region by reducing the p- and n-side SCH layers to 20 , and $70 \mathrm{~nm}$, respectively in a 6-stack InAs/InGaAsP Qdash laser. This was carried out for the purpose of reducing the carrier transit time and to limit the recovery

(A)

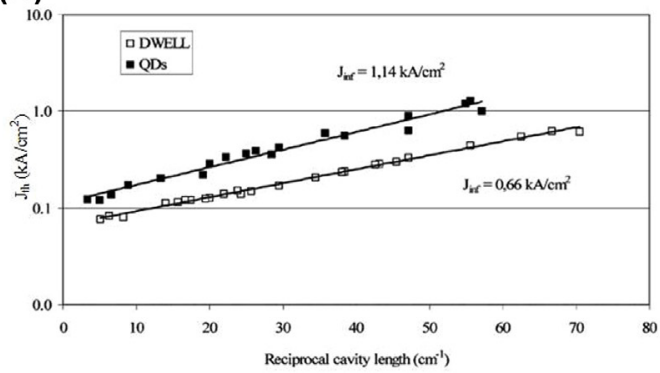

(B)

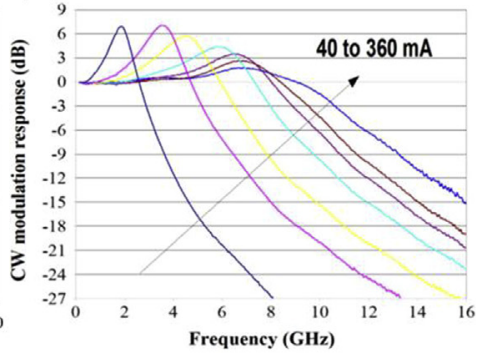

FIG. 5.6

(A) Liner fits in terms of $J_{\text {th }}$ as a function of temperature of $2 \times 700 \mu \mathrm{m}^{2}$ fixed ridgewaveguide InAs/InGaAsP/InP Qdash laser [43]. (B) Small signal modulation response on a $600 \mu \mathrm{m}$ as-cleaved, reduced SCH layer thickness buried ridge stripe DaWELL laser at $25^{\circ} \mathrm{C} . \mathrm{T}[45]$.

From Khan MZM, Ng TK, Ooi BS. Self-assembled InAs/InP quantum dots and quantum dashes: material structures and devices. Progress in Quantum Electronics 2014;38(6):237-313. 
of the optical mode and the absorbing p-doped waveguiding layers. The $600 \mu \mathrm{m}$ long buried ridge-waveguide laser displayed a relatively flat $\mathrm{RIN}-155 \mathrm{~dB} / \mathrm{Hz}$ $(0.1-16 \mathrm{GHz})$ whereas the relaxation frequency was estimated as $\sim 8.5 \mathrm{GHz}$. More significantly, the obtained small signal modulation bandwidth of $10.5 \mathrm{GHz}$ under CW operation and room temperature is the largest value ever reported on any Qdash material system), as depicted in Fig. 5.6B. Joshi et al. [46] investigated the linewidth enhancement factor associated with p-doping on a 1.25-mm long 6stack Qdash laser with dashes in InGaAsP Quantum wells and InGaAsP barriers that are p-doped utilizing delta type doping. The distributed feedback laser (DFB) laser demonstrated a significant reduction in the linewidth parameter both below and above threshold $(\sim 2)$ suggesting that the carrier population in the wetting and barrier layers is reduced leading to a small number of non-resonant carriers.

In a different study, tunneling injection was investigated by Lelarge et al. $[47,48]$ on the InAs/InGaAsP Qdash laser material system. On a buried ridge-waveguide $1.5 \times 600 \mu \mathrm{m}^{2}$ device, a low $155 \mathrm{~A} / \mathrm{cm}^{2}$ per layer transparency current density and $334 \mathrm{~A} / \mathrm{cm}^{2}$ per layer threshold current density were obtained under CW operation. The slope efficiency and characteristic temperature were estimated as $0.34 \mathrm{~W} /$ A and $50 \mathrm{~K}$, respectively, while RIN measurements yielded a value of $-155 \mathrm{~dB} / \mathrm{Hz}$ from 0.1 to $16 \mathrm{GHz}$. The small signal modulation bandwidth and resonance frequency were measured as $\sim 8.5$ and $4.5 \mathrm{GHz}$, respectively, with the latter exhibited parasitic-like roll off that was likely related to the carrier transport limitations [48]. The observed minimal impact of tunneling injection scheme on the laser dynamics was likely correlated to the significant carrier escape from the injector-Qdash ensembles. As such, this can be improved with higher energy barriers and carrier confinement or by adopting a moderate p-doping scheme in tandem with tunneling injection as has been adopted by Mi et al. [21] as discussed earlier.

When it comes to the static performance characteristics, Zhou et al. $[49,50]$ reported the smallest value of threshold current density $\left(72 \mathrm{~A} / \mathrm{cm}^{2}\right.$ per layer) and transparency current density $\left(45 \mathrm{~A} / \mathrm{cm}^{2}\right.$ per layer) on a InAs/InGaAsP Qdash material system. The 5-stack Qdash-in-barrier SCH laser structure was grown through the optimized double-cap technique, and employing a $2.2 \mathrm{~nm}$ cap with a 30 -s growth interruption. The obtained internal quantum efficiency of the $\sim 1.55-1.58 \mu \mathrm{m}$ emitting laser was $58 \%$ whereas the internal loss was estimated as $7 \mathrm{~cm}^{-1}$. Later on, the lowest internal loss value $\left(2.7 \mathrm{~cm}^{-1}\right)$ on any Qdash material system was reported by Faugeron et al. [51] with a high internal quantum efficiency of $81 \%$ on a 6 -stack Qdash-in-barrier laser of asymmetric-cladding that was lasing around $1.59 \mu \mathrm{m}$. The slope efficiency was estimated as 0.32 W/A whilst the threshold current density was obtained as $\sim 4 \mathrm{kA} / \mathrm{cm}^{2}$. Very recently, Pes et al. [34] reported a continuouswave $1.6 \mu \mathrm{m}$-emitting optically-pumped InAs Qdash based vertical-external-cavity surface-emitting laser. In multi-transverse mode operation, the maximum output power was measured as $163 \mathrm{~mW}$ at $20^{\circ} \mathrm{C}$ from $12 \mathrm{~mm}$-long cavity whereas when the laser was made single-frequency, the maximum measured output power was $7.9 \mathrm{~mW}$ at $19.5^{\circ} \mathrm{C}$ in a $49 \mathrm{~mm}$-long cavity. The laser device showed a wavelength tunability between 1609 and $1622 \mathrm{~nm}$ in the latter condition while the linewidth 
was estimated as $22 \mathrm{kHz}$. Furthermore, Class-A operation was demonstrated with a RIN level of $135 \mathrm{~dB} / \mathrm{Hz}$ at $100 \mathrm{kHz}$ and a cut-off frequency of $800 \mathrm{kHz}$.

\subsection{InAs/InP Qdash ultra-broadband lasers}

Our group was first to demonstrate and exploit the highly inhomogeneous nature of a multi-stack InAs/InGaAlAs Qdash active region [52] as a broadband emitting device. As depicted in Fig. 5.6A, a lasing bandwidth of $\sim 22 \mathrm{~nm}$ centered at $\sim 1.64 \mu \mathrm{m}$ was reported on a 4 -stack $50 \times 600 \mu \mathrm{m}^{2}$ laser that exhibited a perlayer pulsed threshold current density of $650 \mathrm{~A} / \mathrm{cm}^{2}$ and a slope efficiency of $0.165 \mathrm{~W} / \mathrm{A}$ with an output power $>400 \mathrm{~mW}$. The emission coverage was able to be pushed later on to $85 \mathrm{~nm}$ with a $\sim 41-\mathrm{nm}$ bandwidth by Tan et al. [53] via a $50 \times 500 \mu \mathrm{m}^{2}$ as-cleaved intermixed laser that is also shown in Fig. 5.7A. Moreover, a lower threshold current density $\left(525 \mathrm{~A} / \mathrm{cm}^{2}\right.$ per layer) was achieved with a slope efficiency of $0.423 \mathrm{~W} / \mathrm{A}$, and a characteristics temperature $\mathrm{T}_{0} \sim 57$. Subsequently, our group successfully reported [6] a record $\sim 50 \mathrm{~nm}$ lasing bandwidth and lasing emission coverage of $\sim 65 \mathrm{~nm}$ via a chirped barrier 4-stack Qdash active regionbased $2 \times 830 \mu \mathrm{m}^{2}$ ridge-waveguide laser, as shown in Fig. 5.7B. The laser displayed a per-layer threshold current density of $900 \mathrm{~A} / \mathrm{cm}^{2}$ and a slope efficiency 0.36 W/A. Furthermore, we investigated the device physics of the chirped structure and postulated that simultaneous emission for dispersive Qdashes [33] and the nonuniform distribution of carriers in the Qdash active region [32] play a significant role in the observed broad emission. Very recently, we further investigated the detailed thermal characteristics of the InAs/InP Qdash broadband laser with different ridge widths in terms of junction and characteristics temperatures [54]. The results dictated an inverse relation between the ridge-width and the junction temperature.

(A)

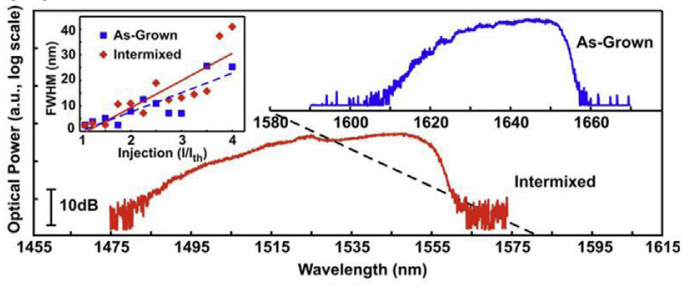

(B)

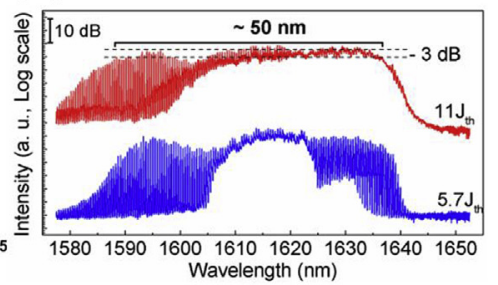

FIG. 5.7

(A) The wavelength tuned broadband fixed barrier 4 stack InAs/InGaAIAs DaWELL laser from $1.64 \mu \mathrm{m}$ (as-grown) to $1.54 \mu \mathrm{m}$ (IFVD intermixed) center wavelength. The lasing coverage increases from 76 to $85 \mathrm{~nm}$ after the intermixing process. The inset shows the $-3 \mathrm{~dB}$ bandwidth of the broadband Qdash laser in accordance to injection [53]. (B) Room temperature lasing spectra of $2 \times 830 \mu \mathrm{m}^{2}$ chirped barrier thickness 4 stack InAs/ InGaAIAs DaWELL laser at different pulsed injection current density [6].

From Khan MZM, Ng TK, Ooi BS. Self-assembled InAs/InP quantum dots and quantum dashes: material structures and devices. Progress in Quantum Electronics 2014;38(6):237-313. 
(A)

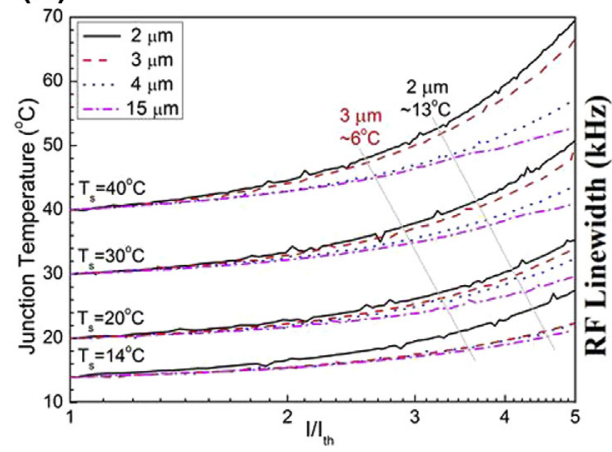

(B)

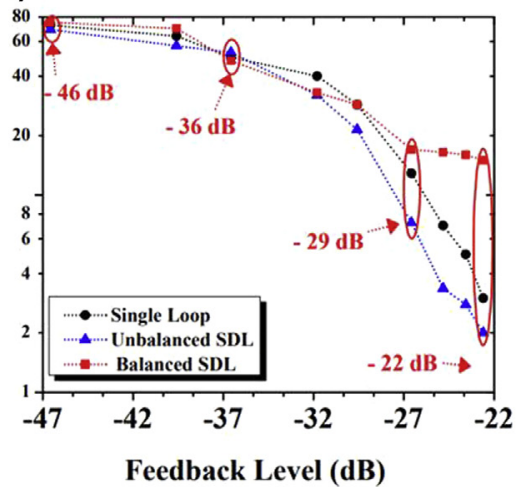

FIG. 5.8

(A) Estimated rise in the junction temperature of all the $\ln A s / \ln P$ Qdash laser devices at four different heat sink temperatures, as a function of injection current I/Ith. (B) RF linewidth under resonant condition in the case of single loop, unbalanced and balanced symmetrical dual-loop feedback configurations as a function of external feedback ratio at a bias of $300 \mathrm{~mA}$ showing $-22 \mathrm{~dB}$ to be the optimum value, in the case of single, balanced and unbalanced symmetrical dual-loop feedback configurations.

From Khan MZM, Ng TK, Ooi BS. Self-assembled InAs/InP quantum dots and quantum dashes: material structures and devices. Progress in Quantum Electronics 2014;38(6):237-313. Also reprinted with permission from Asghar $\mathrm{H}$, et al. Stabilization of self-mode-locked quantum dash lasers by symmetric dual-loop optical feedback. Optical Express 2018;26(4):4581-92.

The narrowest $2 \mu \mathrm{m}$ ridge width which demonstrated the largest lasing bandwidth of $\sim 50 \mathrm{~nm}$, exhibited highest thermal resistance of $\sim 45^{\circ} \mathrm{C} / \mathrm{W}$ and hence the largest junction temperature buildup, as illustrated in Fig. 5.8A. This further affirmed thermionic carrier escape and phonon-assisted tunneling to be the dominant carrier transport mechanisms resulting in the non-uniform distribution of carriers, and thus broadband lasing from this device.

\subsection{InAs/InP Qdash single mode lasers}

On the other hand, few studies have been concocted on single mode Qdash lasers. For the InAs/InGaAlAs material system, Kaiser et al. [55] reported a small signal modulation bandwidth of $7.6 \mathrm{GHz}$ from a $3 \times 1000 \mu \mathrm{m}^{2}$ laterally coupled DFB gratings based on 4 stack InAs/InGaAlAs Qdash laser. The $1.51 \mu \mathrm{m}$ emitting laser exhibited a slope efficiency and an output power of $0.13 \mathrm{~W} / \mathrm{A}$ and $>30 \mathrm{~mW}$, respectively, whereas the SMSR was estimated as $>40 \mathrm{~dB}$. Later, Zeller et al. [56] and Hein et al. [57] were able to improve the relatively inferior performance of the long wavelength InAs Qdash in InGaAs Qwell DFB lasers as they reported single mode emitting lasers at 2.01 and $1.89 \mu \mathrm{m}$, respectively, under $\mathrm{CW}$ operation and at room temperature. The former report utilized a $2 \times 900 \mu \mathrm{m}^{2}$ laser with a 
threshold current of $40 \mathrm{~mA}$ and a high SMSR of $>35 \mathrm{~dB}$. The latter one, on the other hand, displayed a slope efficiency 0.22 W/A with an output power $>25 \mathrm{~mW}$.

In terms of the InAs/InGaAsP material system, Dagens et al. [58] reported a $4.8 \mathrm{~mA}$ threshold current, $45.5 \mathrm{~dB}$ SMSR, and a $0.3 \mathrm{~W} / \mathrm{A}$ slope efficiency from a $0.8 \times 205 \mu^{2}$ a 6 -stack DaWELL buried ridge-waveguide DFB laser emitting at $1.51 \mu \mathrm{m}$ grown via MBE-MOCVD. The small signal modulation bandwidth was obtained as $\sim 6.7 \mathrm{GHz}$ with a high modulation efficiency of $1.9 \mathrm{GHz} / \mathrm{mA}^{0.5}$ and a $\mathrm{K}$-factor $0.43 \mathrm{~ns}$ [28]. Subsequently, the direct small signal modulation bandwidth was successfully pushed to $\sim 10 \mathrm{GHz}$ with a low $\mathrm{K}$-factor of $0.3 \mathrm{~ns}$ and a reduced above-threshold LEF of $<2$ by Lelarge et al. [59]. This was achieved by reducing the $\mathrm{SCH}$ layer thickness in a $0.5 \mathrm{~mm}$ and $1.0 \mathrm{~mm}$ long buried ridge-waveguide DFB lasers emitting at $1.54 \mu \mathrm{m}$ with a SMSR of $\sim 40 \mathrm{~dB}$.

\subsection{InAs/InP Qdash injection locked laser}

Optical injection under stable locking conditions has the potential to enhance the dynamic characteristics of InAs/InP Qdash lasers as has been demonstrated by Li et al. [60] as he reported a three times increase in the small signal modulation bandwidth of $4 \times 500 \mu \mathrm{m}^{2}$ injection-locked laser. The $3 \mathrm{~dB}$ bandwidth at a $-8.6 \mathrm{dBm}$ injected power was $8.7 \mathrm{GHz}$ compared to the $3.4 \mathrm{GHz}$ value of the free-running case. Naderi et al. [61] were able to push that value further to $11.7 \mathrm{GHz}$ with a SMSR value of $30 \mathrm{~dB}$ corresponding to three times increase over the free-running case. Later, a remarkable $16.5 \mathrm{GHz}$ small signal modulation $-3 \mathrm{~dB}$ bandwidth was reported by Lester et al. [62]. This four-fold increase in the bandwidth was achieved through a slightly blue shifted $(1.535 \mu \mathrm{m})$ injection locked Qdash laser under strong optical injection of $9.3 \mathrm{~dB}$. Moreover, a striking near zero above-threshold LEF and a differential gain of $5.9 \times 10^{-14} \mathrm{~cm}^{-2}$ were acquired.

A rigorous dynamic investigation of an injection-locked Qdash laser was subsequently concocted by Pochet et al. $[63,64]$ at zero detuning where it was shown that the a high gain compression coefficient and a large damping rate in addition to a sufficiently small LEF value are operating conditions for stable locking at nearthreshold biasing currents. Whilst optical injection can indeed enhance the performance characteristics of Qdash lasers, it can conversely impact the stability of the laser resulting in collapsing the coherence time and broadening the emission spectrum in addition to degrading the LEF and bit error rate (BER). As such, Azouigui et al. [65] investigated the tolerance of Qdash lasers to the optical feedback as it was demonstrated that increasing the current injection of a $205-\mu \mathrm{m}$ long InAs/InGaAsP Qdash DFB laser from 10 to $100 \mathrm{~mA}$ yielded in a coherence collapse from $\sim-41$ to $-27 \mathrm{~dB}$. Later on, high differential gain devices were shown to have a better performance from this point of view with an onset of coherence collapse as good as $>-18 \mathrm{~dB}$ [66]. Furthermore, temperature insensitive differential gain laser and/or longer cavity devices were shown to be able to achieve higher optical feedbacks [67]. Contrary to that and opposite to the case with Qwell lasers, Grillot et al. [68] demonstrated that increasing the current injection of a $500-\mu \mathrm{m}$ long ridge- 
waveguide Qdash laser decreased the critical feedback level which was ascribed to the increased non-linear increase of the GS above-threshold LEF from $\sim 1$ to $\sim 14$ associated with the increased current injection. This since has been adopted as a key parameter in design of Qdash lasers that are feedback-resistant [69]. Sadeev et al. [70] utilized dual-mode optical injection on a single-mode buried InP/InAs Qdash laser with a $1-\mu \mathrm{m}$ ridge width and emitting at $1.55-\mu \mathrm{m}$. A maximum normalized conversion efficiency value of $-17 \mathrm{~dB}$ was reported with an OSNR of $37 \mathrm{~dB}$ at a $27 \mathrm{GHz}$ detuning with a wide detuning range from -1.2 to $2.7 \mathrm{THz}$.

\subsection{InAs/InP Qdash mode-locked lasers}

With the aid of mode-locking techniques, the broadly emitting InAs/InP Qdash lasers are capable of sub-picosecond pulse generation which has made them a hot focus of research for the past few years as they have demonstrated remarkable improved performance parameters including, repetition frequency, pulse width, and ultra-small RF linewidth, in the range between $<1 \mathrm{kHz}$ and $600 \mathrm{kHz}[28,61]$. Gosset et al. [71] were first to demonstrate passive mode-locking by utilizing a two-section InAs/InGaAsP Qdash laser where one section acts as a gain section while the other as an absorber. The 6-stack Qdash laser exhibited a RF linewidth of $47 \mathrm{kHz}$ with a gain and absorber sections that are 940 and $180 \mu \mathrm{m}$ in length, respectively. The resulting pulsation frequency was $43.6 \mathrm{GHz}$ under a $\mathrm{CW}$ biasing current of $169 \mathrm{~mA}$. Subsequently, the timing jitter and phase noise were investigated by Dontabactouny et al. [72] on a $1.59 \mu \mathrm{m}$ emitting 5 stacks InAs/InGaAsP Qdash laser whose gain and absorber sections were 3.95 and $0.13 \mathrm{~mm}$, respectively. With a fixed biasing current and reverse biasing voltage, highly chirped pulses in the range between 8 and 14 ps were generated with a pulsation frequency of $10 \mathrm{GHz}$ by tuning the passband window of a $1 \mathrm{~nm}$ bandwidth filter that was centered at $1.6 \mu \mathrm{m}$. With the aid of a 545-m long single mode fiber for the purpose of dispersion compensation, the pulses were able to be pushed down to a lowest value of 975 fs after deconvolution. Furthermore, a low timing jitter value of 800 fs was obtained while the phase noise measurements displayed $-80 \mathrm{dBc} / \mathrm{Hz}$ at $100 \mathrm{kHz}$ which was then reduced down to $-140 \mathrm{dBc} / \mathrm{Hz}$.

Rosales et al. concocted a series of systematic investigations [73-75] on three InAs/InGaAsP Qdash lasers with cavity lengths of 1200,890 , and $450 \mu \mathrm{m}$ and a $10 \%$ absorber section. The obtained respective repetition rates were 20,48 and $95 \mathrm{GHz}$ with the latter value being the highest reported on any InAs/InP Qdash monolithic two-section device. Mode-locking was achieved at a fairly large reverse bias with deconvolved pulse durations of $\sim 1.4, \sim 2.5$ and $\sim 1.6$ ps for the long, medium, and short devices respectively. Recently, Asghar et al. [76] analyzed in detail the effects of optical feedback single- and dual-loops on the pulse trains generated by a two-sectioned Qdash laser emitting at $1.55 \mu \mathrm{m}$ with a repetition range of $20 \mathrm{GHz}$. The investigation aimed to identify the optimal feedback level that achieves minimum RF linewidth and hence lowest timing jitter. As Fig. 5.8B shows, a $\sim-22 \mathrm{~dB}$ feedback level was shown to achieve a high suppression of the RF 
linewidth from $98 \mathrm{kHz}$ (in the case of free-running) to 5 and $1.5 \mathrm{kHz}$ for the singleand dual-loop configurations, respectively. Moreover, the corresponding timing jitter was measured as $\sim 800$ and $\sim 500$ fs for the single- and dual-loop configurations, respectively, compared to the $\sim 4.8$ ps associated with the free-running case. Very recently, it was demonstrated that [77] employing an unbalanced symmetric dualloop configuration in tandem with a full tuning of delay phase of the second feedback cavity resulted in narrower RF linewidths $(1.5 \mathrm{kHz})$ and reduced timing jitter (450 fs) across the widest delay range at the same optical feedback level of a $\sim-22 \mathrm{~dB}$ when compared to single ( $3 \mathrm{kHz}$ RF linewidth and $600 \mathrm{fs}$ timing jitter) and balanced symmetric dual-loop feedback systems.

Compared to two-section mode locking, passive singe-section mode locking (self-pulsation) is more favorable from different points of view, such as achievable power and pulse width, and thus have been adopted by researchers for the past decade showing a superior performance. As such, Gosset et al. [71] were first to report a mono-section mode locking in a Qdash material system. A $134 \mathrm{GHz}$ pulse generation was reported on a 6-stack $340 \mu \mathrm{m}$ long InAs/InGaAsP DaWELL laser operating at $1.56 \mu \mathrm{m}$ under $\mathrm{CW}$ bias. A sub-picosecond pulse width of $800 \mathrm{fs}$ without deconvolution or pulse compression was measured with a $50 \mathrm{kHz} \mathrm{RF}$ spectral linewidth. Moreover, the pulse repetition rate was reported to be $42.2 \mathrm{GHz}$ with 2 ps auto-correlated pulses. Shen et al. [78] demonstrated the viability in employing optical filters in order to limit the beating linewidth to $2 \mathrm{kHz}$ on a $17 \mathrm{GHz}, 2.5 \mathrm{~mm}$ long Qdash mode-locked laser (QD-MLL). Later on, reducing the optical confinement factor was show to have a similar effect on the beating linewidth [79]. It was postulated that this was owning to the reduced optical mode interactions with the amplified spontaneous emission, and large population inversion, leading to a reduced phase noise $[73,80]$.

Alternatively, the mode-beating linewidth (phase noise) was reduced from $30 \mathrm{kHz}(-75 \mathrm{dBc} / \mathrm{Hz})$ to a mere $200 \mathrm{~Hz}(-105 \mathrm{dBc} / \mathrm{Hz})$ by Akrout et al. [81] via employing an external cavity length based high quality factor in an auto-optical feedback loop for initial phase noise reduction. This was carried out on a selfpulsating 30.3 GHz InAs/InGaAsP/InP QD-MLL. In terms of the timing jitter, Latkowski et al. [82] utilized a 450-m long single mode dispersion-compensated fiber and demonstrated 720-fs wide pulses via a 39.8 GHz QD-MLL. Moreover, independently of the biasing current, a beating linewidth of $10-25 \mathrm{kHz}$ was obtained with a timing jitter that varied from 350 to 150 fs while the peak power varied from 40 to $140 \mathrm{~mW}[83,84]$, as shown in Fig. 5.9A. It was found that increasing the bias current or the filter bandwidth resulted in a reduction in the pulse width which was ascribed to the superior phase locking at higher injection and larger number of locked longitudinal modes $[85,86]$.

On another front, a record repetition rate of $346 \mathrm{GHz}$ was reported by Merghem et al. [87] as depicted in see Fig. 5.9B by employing a 120- $\mu \mathrm{m}$ long Qdash laser emitting $~ 560$ fs deconvolved pulses of a peak power of $20 \mathrm{~mW}$ and an extinction ratio of $9 \mathrm{~dB}$. Later on, a detailed investigation [88] on the repetition frequency stability was carried out on a $10 \mathrm{GHz}$ Qdash passively mode-locked laser. Furthermore, 
(A)
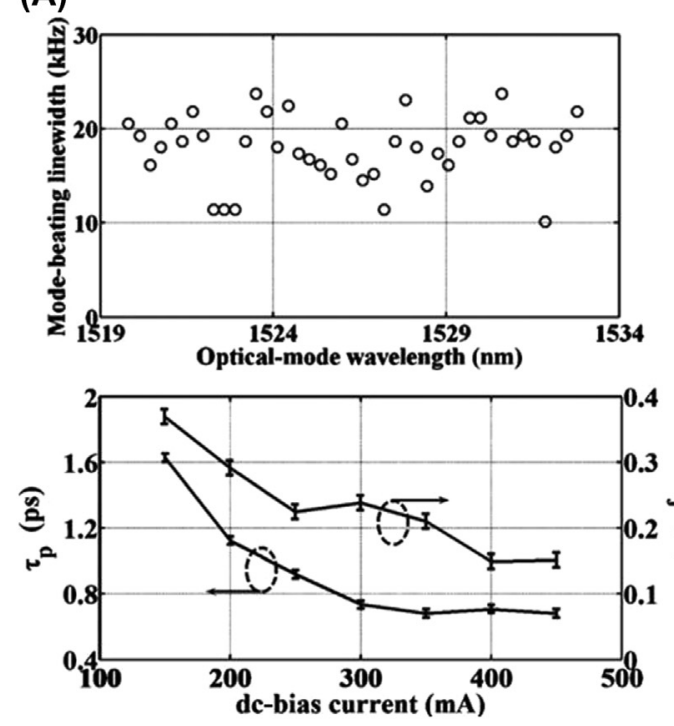

(B)

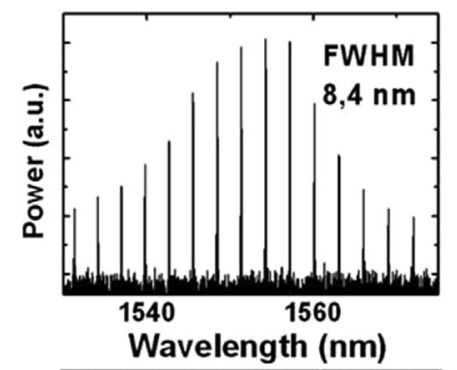

FIG. 5.9

(A) Typical mode-beating associated with each pair of optical modes as a function of the filter central wavelength (top) of the $1000 \mu \mathrm{m}$ long $40 \mathrm{GHz}$ InAs/InGaAsP Qdash modelocked laser at $350 \mathrm{~mA}$. The corresponding device pulse width and timing jitter associated with the optically generated pulses as a function of CW current (bottom) [84]. (B) Optical spectrum (top) and autocorrelation trace (bottom) of $120 \mu \mathrm{m}$ long, $345 \mathrm{GHz}$, InAs/ InGaAsP Qdash mode-locked laser at $217 \mathrm{~mA}$ [87].

From Khan MZM, Ng TK, Ooi BS. Self-assembled InAs/InP quantum dots and quantum dashes: material structures and devices. Progress in Quantum Electronics 2014;38(6):237-313.

an electrical and an optical feedback loops were developed and demonstrated to improve the initial long-term stability of the free-running case $\sim 10^{-7}$ to a longterm stability of $3 \times 10^{-9}$ in the case of the electrical feed-back system and to $1.5 \times 10^{-9}$ in the case of the optical feed-back system.

By employing the second-harmonic generation frequency resolved optical gating (SHG-FROG) technique, Calò et al. [89] investigated a high gain $\sim 50 \mathrm{~cm}^{-1}, 890-$ $\mu \mathrm{m}$ long device, 9-stack InAs/InGaAsP dash-in-barrier laser. The $1.56 \mu \mathrm{m}$ emitting device showed a $\sim 48 \mathrm{GHz}$ repetition frequency under $\mathrm{CW}$ operation. Highly chirped 423 fs pulses were achieved through a single mode fiber with a peak power of $\sim 100 \mathrm{~mW}$ peak power at $300 \mathrm{~mA}$ biasing current. This was however was further reduced later [90] to $374 \mathrm{fs}$ at $400 \mathrm{~mA}$ which is the best reported value on any InAs/ InP Qdash material system. Later, a record peak power of $18 \mathrm{~W}$ was reported by Faugeron et al. [51] by developing an asymmetrical cladding 10-mm long, 4.4 GHz, single-section Qdash laser with a narrow RF linewidth of $300 \mathrm{~Hz}$. The Qdash laser emitted 750 fs deconvolved pulses post-compression and $9.3 \mathrm{ps} / \mathrm{nm}$ 
compensation via a 570-m long single mode fiber. Furthermore, an improved phase noise $<-100 \mathrm{~dB} / \mathrm{Hz}$ at an offset frequency of $1 \mathrm{kHz}$ and $\mathrm{RF}$ harmonics up to $120 \mathrm{GHz}$ were also reported on a 4.3-mm long Qdash laser [29].

In another study, Sooudi et al. [91] utilized double locking with simultaneous optical injection and optical feedback on QD-MLL and reported a reduction of two times in the bandwidth product and two orders of magnitude reduction in the RF linewidth. This work was followed by an implementation of dual-loop feedback in tandem with optical injection and optical fiber delay by Wei et al. [92] on a $1.55 \mu \mathrm{m}, 20 \mathrm{GHz}$ InAs/InP DaWELL. As such, the RF linewidth and timing jitter were significantly reduced from $97.9 \mathrm{kHz}$ to $4.27 \mathrm{ps}$, respectively in the case of free-running, to $972 \mathrm{~Hz}$ and $430 \mathrm{fs}$. Moreover, a reduction in the phase noise from $-74 \mathrm{dBc} / \mathrm{Hz}$ to $-87 \mathrm{dBc} / \mathrm{Hz}$ at $100 \mathrm{kHz}$ frequency offset was also reported.

\section{InAs/InP Qdash lasers in optical communications}

Over the past decade, network traffic and increases in consumer demands are producing significant challenges to continue optical communications on costeffective scale. In today's digital information society, large number of applications demands high bit rate to accommodate individual users. Several hundred Terabit/s per chip will be required for next generation system architectures over the next few years. Meeting those demands will require new forms of optical solutions. One of the promising solutions are addressed by the employment of Qdash based mode-locked or injection-locked lasers as multiwavelength or transmitter sources for WDM system, owing to their notable broadband lasing emission properties with reduced RIN. This feature of Qdash lasers appears to be highly attractive for next-generation passive optical networks (NG-PONs) as well. In this section, we discuss various demonstration of employment of Qdash lasers in as a source in optical communications.

\subsection{InAs/InP Qdash mode-locked lasers}

Akrout et al. was the first to propose and demonstrate $10 \mathrm{~Gb} / \mathrm{s}$ on-off keying (OOK) transmission of eight WDM channels via a single QD-MLL over 50-km single-mode fiber (SMF) [93]. As compared to the single-mode distributed feedback laser, a WDM comb generation emitting at $1.55 \mu \mathrm{m}$ was utilized with $100-\mathrm{GHz}$ channel spacing. Subsequently, QD-MLL as seeding light source was reported by Nguyen et al. [94] for colorless WDM passive optical networks. A bidirectional transmission of $2.5 \mathrm{~Gb} / \mathrm{s}$ was demonstrated for $16 \mathrm{WDM}$ channels over $25 \mathrm{~km} \mathrm{SMF}$ in the C-band. As a coherent multiwavelength seeding source, a QD-MLL is optically injected into wavelength-locked typical Fabry-Perot laser diode (FP-LD) with mode spacing of 42.7-GHz.

Taking advantages of mode-locked laser diodes, M. Costa e Silva et al. [95] demonstrated first $4 \times 170 \mathrm{~Gb} / \mathrm{s}$ capacity dense WDM transmission using single 
QD-MLL source. The four channels were transmitted over 100 SMF length. Later, comb generation with nine $C$-band WDM channels were investigated by M'Sallem et al. [96]. An external modulation of $56 \mathrm{~Gb} / \mathrm{s}$ differential quaternary phase-shift keying (DQPSK) transmission was reported based on 100-GHz WDM grid using a single QD-MLL for broadcast applications. Later, Gay et al. demonstrated $112 \mathrm{~Gb} / \mathrm{s}$ WDM transmission of four dense WDM (DWDM) channels using a single QD-MLL followed by a SOA in order to reduce mode partition noise [97]. Each channel is directly modulated at $28 \mathrm{~Gb} / \mathrm{s}$ in OOK format after $100 \mathrm{~km}$ fiber. Alternatively, feed forward heterodyne [98] and self-homodyne [99] detection schemes were employed by J. Pfeifle et al. to reduce the phase noise and optical linewidth of QD-MLL. In Ref. [98], coherent Tbit/s transmission was demonstrated on simultaneous 30 comb lines at 18 Gbaud QPSK signal and over $75 \mathrm{~km}$ fiber, with an aggregate capacity of $\sim 1 \mathrm{Tbit} / \mathrm{s}$. This was further enhanced to an aggregate data rate of $1.562 \mathrm{Tbit} / \mathrm{s}$ with $25 \mathrm{comb}$ lines of QD-MLL via 16 QAM transmission, and at a symbol rate of 18 Gbaud, utilizing self-homodyne system [99].

Recently, by employing optimized QD-MLL with potential applications in data center optical interconnects, Vujicic et al. [100] achieved an aggregate data capacities of $1.128 \mathrm{~Tb} / \mathrm{s}$ and $2.256 \mathrm{~Tb} / \mathrm{s}$ for $44.7 \mathrm{GHz}$ and $22.7 \mathrm{GHz}$ free spectral ranges (FSRs) devices, respectively. WDM transmission of $28.2 \mathrm{~Gb} / \mathrm{s}$ was demonstrated over $3 \mathrm{~km} \mathrm{SMF}$ through 40 (44.7 GHz FSR) and 80 (22.7 GHz FSR) channels using intensity modulation/direct detection (IM/DD) scheme. Moreover, they extended their work with long distance transmission of $50 \mathrm{~km}$ SMF employing 16 (shown in Fig. 5.9), 40 and 80 channels from a single QD-MLL, achieving an aggregate capacity up to $4.5 \mathrm{~Tb} / \mathrm{s}$ for interconnect applications [101]. Fig. 5.10A showed the measured lasing spectrum of $82.8 \mathrm{GHz}$ QD-MLL with $\sim 4 \mathrm{~dB}$ flatness. Bit error rate was measured to determine the channel performance at received optical power of $\sim 0 \mathrm{dBm}$. The results obtained after transmission of $3 \mathrm{~km}$ and $50 \mathrm{~km}$ are shown in Fig. 5.10B below the 7\% (BER: $4 \times 10^{-3}$ ) and 20\% (BER: $1.6 \times 10^{-2}$ ) forwarderror correction (FEC) thresholds, respectively. Fig. 5.10C shows the measured RIN of all 16 modes, with an average measured value from -131 to $-134 \mathrm{~dB}$ / Hz. The constellation diagram for 8 middle channels after $3 \mathrm{~km}$ transmission is shown in Fig. 5.10D.

In terms of the highest data rate in $C$-band and high order modulation format, Kemal et al. [102] reported net data rate of $12 \mathrm{~Tb} / \mathrm{s}$ by employing resonant feedback in QD-MLL. The transmission experiment utilized 32 QAM modulation scheme with a symbol rate of 20 Gbaud over $75 \mathrm{~km}$ SMF. Fig. 5.11A shows the combined spectrum of odd and even channels before modulation (P1) and after modulation (P2), as total of 60 channels were used out of the complete QD-MLL spectrum. The measured BER for seven random channels for back-to-back (BtB) and $75 \mathrm{~km}$ fiber transmission for all channels is shown in Fig. 5.11B which are below the 7\% of FEC BER threshold. To compensate high demand of bandwidth-hungry multiple services, Rosales et al. [103] also demonstrated the potential of QD-MLL for radioover-fiber broadband wireless communication. A direct modulation of $3 \mathrm{~Gb} / \mathrm{s}$ QAM transmission was demonstrated for short indoor communication. 
(A)

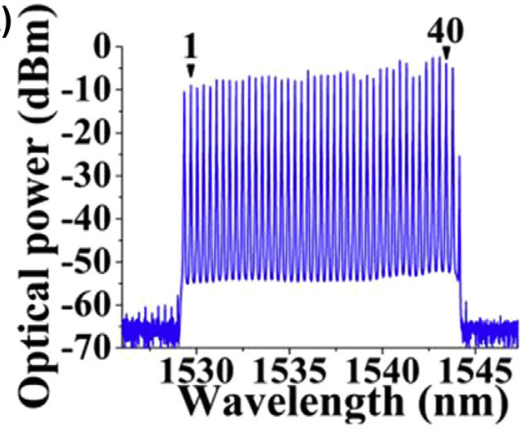

(C)

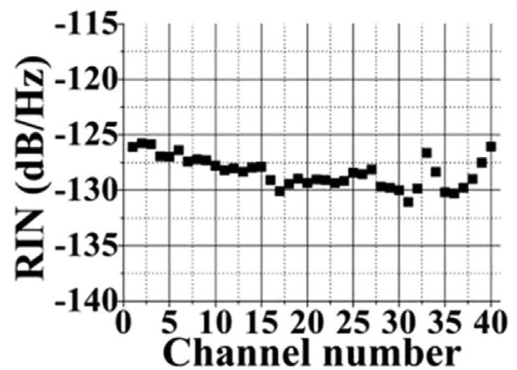

(B)

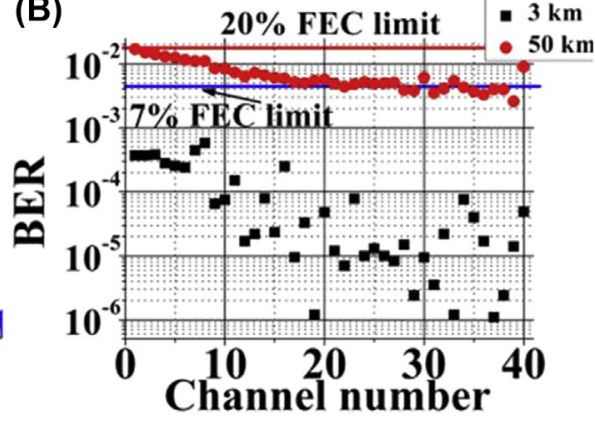

(D)

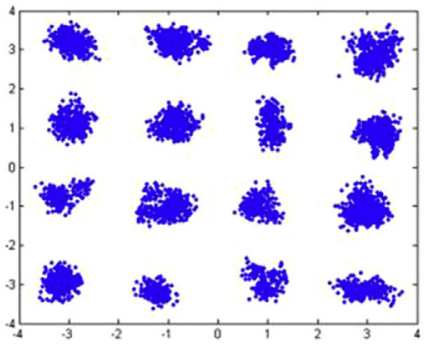

FIG. $\mathbf{5 . 1 0}$

(A) Optical spectrum of Qdash MLL (FSR: $44.7 \mathrm{GHz}$ ) (B) measured bit error rate for each channel over $3 \mathrm{~km}$ and $50 \mathrm{~km}$ fiber transmission (C) Relative intensity noise (RIN) of all modes (D) the constellation diagram over $3 \mathrm{~km}$ of SMF of middle channel.

Reprinted with permission from Vujicic V, Calò C, Watts R, Lelarge F, Browning C, Merghem K, Martinez A, Ramdane A, Barry LP. Quantum dash mode-locked lasers for data centre applications. IEEE Journal of Selected Topics in Quantum Electronics 2015;21(6):53-60.

(A)

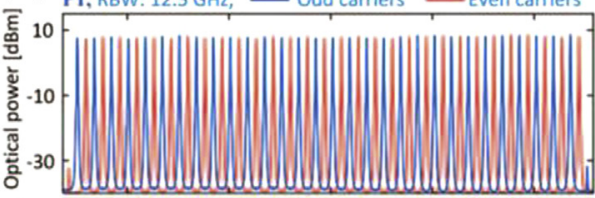

总-20 P2, RBW: $12.5 \mathrm{GHz}$

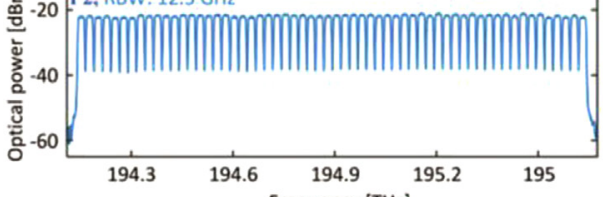

Frequency [THz]
(B)

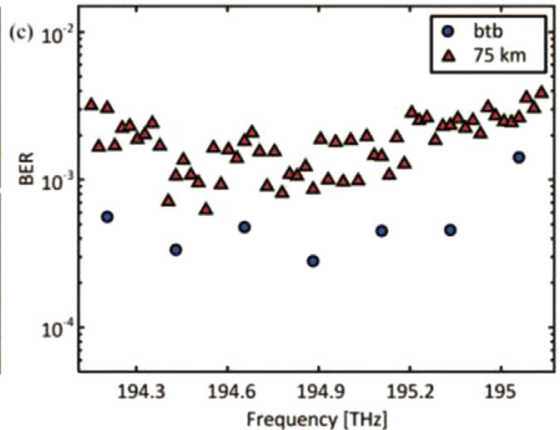

FIG. 5.11

(A) Optical spectra of even and odd channels before modulation (P1), 60 modulated channels (P2) of InAs/InP Qdash MLL (B) Measured bit error rate for BtB and $75 \mathrm{~km}$ fiber transmission.

Reprinted with permission from Kemal JN, Marin-Palomo P, Merghem K, Aubin G, Calo C, Brenot R, Lelarge F, et al. 32QAM WDM transmission using a quantum-dash passively mode-locked laser with resonant feedback. In: 


\subsection{InAs/InP Qdash injection-locked lasers}

Employment of injection-locked InAs/InP Qdash lasers as a transmitter source for next-generation WDM passive optical networks were explored by our group where Khan et al. successfully reported a record $100 \mathrm{~Gb} / \mathrm{s}$ transmission capacity in the far $L$-band, on a single injection-locked channel [104]. The measured single externallylocked Fabry-Perot mode at $\sim 1621 \mathrm{~nm}$ along with free running spectrum of Qdash laser diode, centered at $\sim 1625 \mathrm{~nm}$ is shown in Fig. 5.12A. Moreover, a mode wavelength tunability of $\sim 23 \mathrm{~nm}$, capable of encompassing $\sim 50$ sub-carriers, was also reported, which would enable an aggregate transmission capacity of $\sim 5 \mathrm{~Tb} / \mathrm{s}$ using single QD-LD if injection-locked simultaneously. The measured BER at 32, 64 and $100 \mathrm{~Gb} / \mathrm{s}$ are presented in Fig. 5.12B, which demonstrated the successful transmission below FEC threshold (BER: $3.8 \times 10^{-3}$ ) in BtB and over 10-km SMF while utilizing dual polarization QPSK (DP-QPSK) modulation technique. Alternatively, an injection-locked QD-LD source has also been experimentally demonstrated for future high speed free space optical communication (FSO) by Khan et al. [105]. A single channel $100 \mathrm{~Gb} / \mathrm{s}$ FSO transmission over $4 \mathrm{~m}$ and $2 \mathrm{~m}$ FSO channel was reported in L-band wavelength region. These results demonstrated the potential of far L-band QD-LD as a transmitter source for both fiber and wireless communication.

In addition, our group [106] exploited the self-injection locking scheme to demonstrate a multi-wavelength QD-LD with mode selectivity from 1 to 16
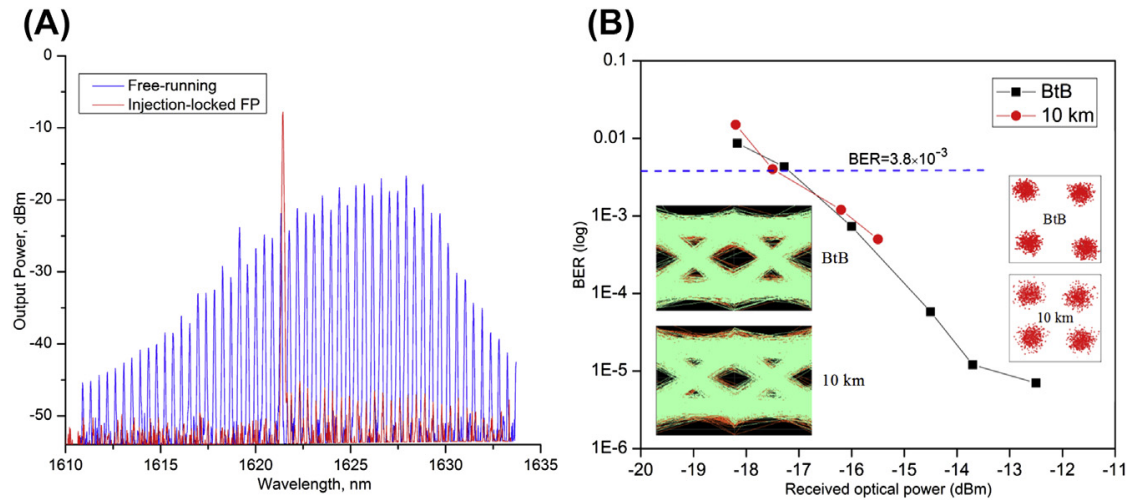

FIG. 5.12

(A) Optical spectra of injection-locked InAs/InP QD-LD (red) and free-running characteristics (blue). (B) Measured BER for $100 \mathrm{~Gb} / \mathrm{s}$ after BtB and $10 \mathrm{~km}$ transmission. Insets show the corresponding QPSK constellations and the eye diagrams.

Reprinted with permission from Khan MTA, et al. $100 \mathrm{~Gb} / \mathrm{s}$ single channel transmission using injection-locked 1621 nm quantum-dash laser. IEEE Photonics Technology Letters 2017;29(6):543-6. 
(A)

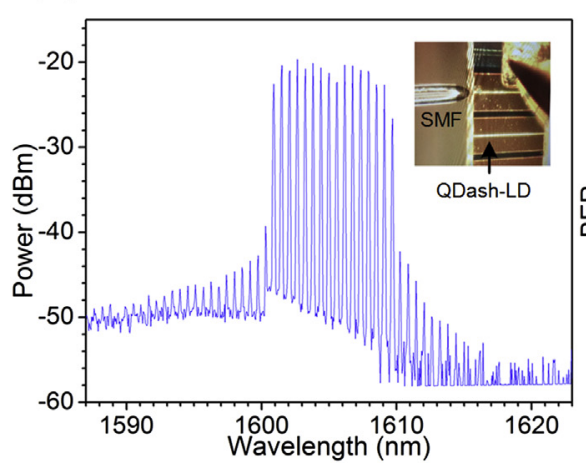

(B)

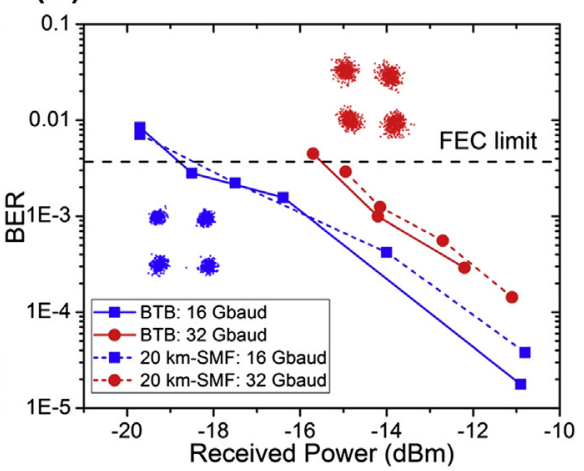

\section{FIG. 5.13}

(A) Optical spectrum of the multiwavelength self-injection locked QD-LD, exhibiting simultaneous 16 locked modes. (B) Measured BER for single self-injection locked mode at $1609.6 \mathrm{~nm}$ for $64 \mathrm{~Gb} / \mathrm{s}$ (blue) and $128 \mathrm{~Gb} / \mathrm{s}$ (red) over BtB and $20 \mathrm{~km} \mathrm{SMF}$ transmission. The insets show the corresponding constellations of both data rates at $-11 \mathrm{dBm}$ received power.

Reprinted with permission from Shemis MA, Ragheb AM, Khan MTA, Fathallah HA, Alshebeili S, Qureshi KK, Khan MZM. L-band quantum-dash self-injection locked multiwavelength laser source for future WDM access networks. IEEE Photonics Journal 2017;9(5):1-7.

channels or locked FP modes in mid $L$-band wavelengths, as shown in Fig. 5.13A. Using a single self-seeded mode a successful transmission of up to $128 \mathrm{~Gb} / \mathrm{s} \mathrm{DP}$ QPSK over $20 \mathrm{~km}$ SMF was reported with measured BER below the FEC limit, as depicted in Fig. 5.13B, with clear constellation diagrams for both transmission rates. Moreover, Shemis et al. also investigated the deployment of this multiwavelength self-seeded QD-LD for future access optical access networks by proposing a plausible next generation PON [106], and over an indoor $5 \mathrm{~m}$ FSO channel [107] in mid L-band, with a potential aggregate capacity of $1.28 \mathrm{~Tb} / \mathrm{s}$.

\section{Acknowledgments}

Authors EAA, MTAK and MZMK gratefully acknowledges the support from King Fahd University of Petroleum and Minerals (KFUPM) grants, SR141002, SR161029 and KAUST004, while TKN, MZMK, and BSO acknowledge the financial support from the King Abdulaziz City for Science and Technology (KACST), Grant No. KACST TIC R2-FP-008. King Abdullah University of Science and Technology (KAUST) funding, BAS/1/1614-01-01, C/M20000-12-001-77. KCR/1/2081-01-01, and GEN/1/6607-01-01. All the authors acknowledge the funding support from KAUST-KFUPM Special Initiative (KKI) Program, EE2381 and $\mathrm{REP} / 1 / 2878-01-01$. 


\section{References}

[1] Bimberg D, Grundmann M, Ledentsov NN. Quantum dot heterostructures. John Wiley \& Sons; 1999.

[2] Zhukov A, Maksimov M, Kovsh A. Device characteristics of long-wavelength lasers based on self-organized quantum dots. Semiconductors 2012;46:1225-50.

[3] Wang R, Stintz A, Varangis P, Newell T, Li H, Malloy K, et al. Room-temperature operation of InAs quantum-dash lasers on InP [001]. IEEE Photonics Technology Letters 2001;13:767-9.

[4] Reithmaier JP, Eisenstein G, Forchel A. InAs/InP quantum-dash lasers and amplifiers. Proceedings of the IEEE 2007;95(9):1779-90.

[5] Khan MZM, Ng TK, Ooi BS. Self-assembled InAs/InP quantum dots and quantum dashes: material structures and devices. Progress in Quantum Electronics 2014;38: 237-313.

[6] Khan MZM, Ng TK, Lee C-S, Bhattacharya P, Ooi BS. Chirped InAs/InP quantumdash laser with enhanced broad spectrum of stimulated emission. Applied Physics Letters 2013;102:091102.

[7] Hsieh Y-S, Ho Y-C, Lee S-Y, Chuang C-C, Tsai J-C, Lin K-F, et al. Dental optical coherence tomography. Sensors 2013;13:8928-49.

[8] Ishida S, Nishizawa N. Quantitative comparison of contrast and imaging depth of ultrahigh-resolution optical coherence tomography images in $800-1700 \mathrm{~nm}$ wavelength region. Biomedical Optics Express 2012;3:282-94.

[9] Kodach V, Kalkman J, Faber D, Van Leeuwen T. Quantitative comparison of the OCT imaging depth at $1300 \mathrm{~nm}$ and $1600 \mathrm{~nm}$. Biomedical Optics Express 2010;1:176-85.

[10] Sharma U, Chang EW, Yun SH. Long-wavelength optical coherence tomography at $1.7 \mu \mathrm{m}$ for enhanced imaging depth. Optics Express 2008;16:19712-23.

[11] Scholle K, Lamrini S, Koopmann P, Fuhrberg P. $2 \mu \mathrm{m}$ laser sources and their possible applications. In: Frontiers in guided wave optics and optoelectronics. INTECH; 2010.

[12] Guo S, Ohno H, Shen A, Matsukura F, Ohno Y. InAs self-organized quantum dashes grown on GaAs (211) B. Applied Physics Letters 1997;70:2738-40.

[13] Utzmeier T, Postigo PA, Tamayo J, Garcia R, Briones F. Transition from self-organized InSb quantum-dots to quantum dashes. Applied Physics Letters 1996;69:2674-6.

[14] Li H, Wu J, Wang Z, Daniels-Race T. High-density InAs nanowires realized in situ on (100) InP. Applied Physics Letters 1999;75:1173-5.

[15] Li H, Zhuang Q, Kong X, Wang Z, Daniels-Race T. Self-organization of wire-like InAs nanostructures on InP. Journal of Crystal Growth 1999;205:613-7.

[16] Schwertberger R, Gold D, Reithmaier J, Forchel A. Epitaxial growth of $1.55 \mu \mathrm{m}$ emitting InAs quantum dashes on InP-based heterostructures by GS-MBE for longwavelength laser applications. Journal of Crystal Growth 2003;251:248-52.

[17] Rotter T, Stintz A, Malloy K. InP based quantum dash lasers with $2 \mu \mathrm{m}$ wavelength. IEEE Proceedings - OptoElectronics 2003:318-21.

[18] Sauerwald A, Kummell T, Bacher G, Somers A, Schwertberger R, Reithmaier J, et al. Size control of InAs quantum dashes. Applied Physics Letters 2005;86: 253112-253112-3.

[19] Sauerwald A, Kümmell T, Löffler A, Somers A, Reithmaier J, Forchel A, et al. Scanning transmission electron microscopy of vertically stacked self organized quantum structures. Physica Status Solidi 2006;3:3947-50. 
[20] Mi Z, Yang J, Bhattacharya P. Growth and characteristics of P-doped InAs tunnel injection quantum-dash lasers on InP. IEEE Photonics Technology Letters 2006;18: 1377-9.

[21] Podemski P, Sek G, Ryczko K, Misiewicz J, Hein S, Höfling S, et al. Columnar quantum dashes for an active region in polarization independent semiconductor optical amplifiers at $1.55 \mu \mathrm{m}$. Applied Physics Letters 2008;93.

[22] González L, García JM, García R, Briones F, Martínez-Pastor J, Ballesteros C. Influence of buffer-layer surface morphology on the self-organized growth of InAs on InP(001) nanostructures. Applied Physics Letters 2000;76:1104-6.

[23] Garcia J, González L, González MU, Silveira JP, González Y, Briones F. InAs/InP (001) quantum wire formation due to anisotropic stress relaxation: in situ stress measurements. Journal of Crystal Growth 2001;227:975-9.

[24] Gendry M, Monat C, Brault J, Regreny P, Hollinger G, Salem B, et al. From large to low height dispersion for self-organized InAs quantum sticks emitting at $1.55 \mu \mathrm{m}$ on InP (001). Journal of Applied Physics 2004;95:4761-6.

[25] Fuster D, González L, González Y, González MU, Martínez-Pastor J. Size and emission wavelength control of InAs/InP quantum wires. Journal of Applied Physics 2005; 98:033502.

[26] Alén B, Martínez-Pastor J, González L, García JM, Molina SI, Ponce A, et al. Sizefiltering effects by stacking InAs/InP (001) self-assembled quantum wires into multilayers. Physical Review B 2002;65:241301.

[27] Lelarge F, Dagens B, Renaudier J, Brenot R, Accard A, van Dijk F, et al. Recent advances on InAs/InP quantum dash based semiconductor lasers and optical amplifiers operating at $1.55 \mu \mathrm{m}$. IEEE Journal of Selected Topics in Quantum Electronics 2007; 13:111-24.

[28] Faugeron M, Tran M, Lelarge F, Chtioui M, Robert Y, Vinet E, et al. High power mode locked quantum dash $1.5 \mu \mathrm{m}$ laser with asymmetrical cladding. In: CLEO: science and innovations; 2012. JW2A.85.

[29] Deubert S, Somers A, Kaiser W, Schwertberger R, Reithmaier J, Forchel A. InP-based quantum dash lasers for wide gain bandwidth applications. Journal of Crystal Growth 2005;278:346-50.

[30] Reithmaier J, Somers A, Deubert S, Schwertberger R, Kaiser W, Forchel A, et al. InP based lasers and optical amplifiers with wire-/dot-like active regions. Journal of Physics D: Applied Physics 2005;38:2088.

[31] Tan C, Djie H, Tan C, Hongpinyo V, Ding Y, Ooi B. The effect of multi active junctions on broadband emission from InAs/InGaAlAs quantum-dash structure. In: LEOS annual meeting conference proceedings, 2009. LEOS'09. IEEE; 2009. p. 147-8.

[32] Khan MZM, Ng T, Lee C-S, Anjum D, Cha D, Bhattacharya P, et al. Distinct lasing operation from chirped InAs/InP quantum-dash laser. IEEE Photonics Journal 2013; 5:1501308.

[33] Khan MZM, Ng TK, Lee C-S, Bhattacharya P, Ooi BS. Investigation of chirped InAs/ InGaAlAs/InP quantum dash lasers as broadband emitters. IEEE Journal of Quantum Electronics 2014;50:51-61.

[34] Pes S, Paranthoën C, Levallois C, Chevalier N, Hamel C, Audo K, Loas G, Bouhier S, Gomez C, Harmand J, Bouchoule S, Folliot H, Alouini M. Class-A operation of an optically-pumped $1.6 \mu \mathrm{m}$-emitting quantum dash-based vertical-external-cavity surface-emitting laser on InP. Optics Express 2017;25:11760-6. 
[35] Schwertberger R, Gold D, Reithmaier J, Forchel A. Long-wavelength InP-based quantum-dash lasers. IEEE Photonics Technology Letters 2002;14:735-7.

[36] Resneau P, Calligaro M, Bansropun S, Parillaud O, Krakowski M, Schwertberger R, et al. High-power and low-noise $1.55 \mu \mathrm{m}$ InP-based quantum dash lasers. In: SPIE photonics Europe; 2004. p. 22-32.

[37] Resneau P, Calligaro M, Krakowski M, Liu H, Hopkinson M, Somers A, et al. High power and very low noise operation at 1.3 and $1.5 \mu \mathrm{m}$ with quantum dot and quantum dash Fabry-Perot lasers for microwave links. In: Optics/photonics in security and defence; 2006. 63990K-63990K-12.

[38] Hein S, Hofling S, Forchel A. Modulation bandwidth and linewidth enhancement factor of high-speed 1.55-m quantum-dash lasers. IEEE Photonics Technology Letters 2009;21:528-30.

[39] Hein S, Podemski P, Sek G, Misiewicz J, Ridha P, Fiore A, et al. Orientation dependent emission properties of columnar quantum dash laser structures. Applied Physics Letters 2009;94:241113.

[40] Djie HS, Wang Y, Ooi BS, Wang D-N, Hwang J, Dang GT, et al. Defect annealing of InAs-InAlGaAs quantum-dash-in-asymmetric-well laser. IEEE Photonics Technology Letters 2006;18:2329-31.

[41] Rudno-Rudziński W, Syperek M, Andrzejewski J, Maryński A, Misiewicz J, Somers A, Höfling S, Reithmaier JP, Sek G. Carrier delocalization in InAs/InGaA1As/InP quantum-dash-based tunnel injection system for $1.55 \mu \mathrm{m}$ emission. AIP Advances 2017;7:015117.

[42] Moreau G, Azouigui S, Cong D-Y, Merghem K, Martinez A, Patriarche G, et al. Effect of layer stacking and p-type doping on the performance of InAs/InP quantum-dash-ina-well lasers emitting at 1.55 $\mu \mathrm{m}$. Applied Physics Letters 2006;89:241123-2411233.

[43] Moreau G, Martinez A, Merghem K, Guilet S, Bouchoule S, Patriarche G, et al. InAs/ InP quantum dash based electro optic modulator with over $70 \mathrm{~nm}$ bandwidth at $1.55 \mu \mathrm{M}$. In: IEEE 19th international conference on indium phosphide \& related materials, 2007. IPRM'07; 2007. p. 271-3.

[44] Lelarge FB, Rousseau R, Martin B, Poingt F, LeGouezigou F, Le Gouezigou OPL. Effect of P-doping on temperature and dynamic performances of $1550 \mathrm{~nm}$ InAs/InP Quantum Dash based lasers. 2009.

[45] Dagens B, Make D, Lelarge F, Rousseau B, Calligaro M, Carbonnelle M, et al. High bandwidth operation of directly modulated laser based on quantum-dash InAs-InP material at $1.55 \mathrm{~m}$. IEEE Photonics Technology Letters 2008;20:903-5.

[46] Joshi S, Chimot N, Ramdane A, Lelarge F. On the nature of the linewidth enhancement factor in p-doped quantum dash based lasers. Applied Physics Letters 2014;105: 241117.

[47] Duan GH, Shen A, Akrout A, Dijk FV, Lelarge F, Pommereau F, et al. High performance InP-based quantum dash semiconductor mode-locked lasers for optical communications. Bell Labs Technical Journal 2009;14:63-84.

[48] Lelarge F, Rousseau B, Martin F, Poingt F, Le Gouezigou L, Le Gouezigou O, et al. Optimization of tunneling-injection InAs/InP (100) quantum dashes lasers for highspeed optoelectronic devices. In: IEEE 19th international conference on indium phosphide \& related materials, 2007. IPRM'07; 2007. p. 274-7. 
[49] Zhou D, Piron R, Dontabactouny M, Dehaese O, Grillot F, Batte T, et al. Low threshold current density of InAs quantum dash laser on InP (100) through optimizing double cap technique. Applied Physics Letters 2009;94:081107.

[50] Zhou D, Piron R, Dontabactouny M, Dehaese O, Grillot F, Batte T, et al. Lowthreshold current density InAs quantum dash lasers on InP (100) grown by molecular beam epitaxy. Electronics Letters 2009;45:50-1.

[51] Faugeron M, Lelarge F, Tran M, Robert Y, Vinet E, Enard A, et al. High peak power, narrow RF linewidth asymmetrical cladding quantum-dash mode-locked lasers. IEEE Journal of Selected Topics in Quantum Electronics 2013;19.

[52] Djie HS, Tan CL, Ooi BS, Hwang J, Fang X-M, Wu Y, et al. Ultrabroad stimulated emission from quantum-dash laser. Applied Physics Letters 2007;91: 111116-111116-3.

[53] Tan C, Djie HS, Wang Y, Dimas CE, Hongpinyo V, Ding YH, et al. Wavelength tuning and emission width widening of ultrabroad quantum dash interband laser. Applied Physics Letters 2008;93:111101.

[54] Alkhazraji E, Khan MTA, Khan MZM. Effect of temperature and ridge-width on the lasing characteristics of InAs/InP quantum-dash lasers: a thermal analysis view. Optics \& Laser Technology 2018;98:67-74.

[55] Kaiser W, Mathwig K, Deubert S, Reithmaier J, Forchel A, Parillaud O, et al. Static and dynamic properties of laterally coupled DFB lasers based on InAs/InP QDash structures. Electronics Letters 2005;41:808-10.

[56] Zeller W, Legge M, Somers A, Kaiser W, Koeth J, Forchel A. Singlemode emission at $2 \mu \mathrm{m}$ wavelength with InP based quantum dash DFB lasers. Electronics Letters 2008; 44:354-6.

[57] Hein S, Somers A, Kaiser W, Höfling S, Reithmaier J, Forchel A. Singlemode InAs/InP quantum dash distributed feedback lasers emitting in $1.9 \mu \mathrm{m}$ range. Electronics Letters 2008;44:527-8.

[58] Dagens B, Make D, Le Gouezigou O, Provost J, Lelarge F, Accard A, et al. First demonstration of $10 \mathrm{~Gb} / \mathrm{s}$ direct modulation with a buried ridge distributed feedback laser based on quantum dash InAs/InP material at $1.55 \mu \mathrm{m}$. In: European conference on optical communications, 2006. ECOC 2006; 2006. p. 1-2.

[59] Lelarge F, Chimot N, Rousseau B, Martin F, Brenot R, Accard A. Chirp optimization of 1550nm InAs/InP Quantum Dash based directly modulated lasers for 10Gb/s SMF transmission up to $65 \mathrm{Km}$. In: International conference on indium phosphide \& related materials (IPRM), 2010; 2010. p. 1-3.

[60] Li YN, Kovanis N, V Lester L. Modulation response of an injection-locked $1550 \mathrm{~nm}$ quantum dash semiconductor laser. 2007.

[61] Naderi NA, Pochet M, Grillot F, Terry NB, Kovanis V, Lester LF. Modeling the injection-locked behavior of a quantum dash semiconductor laser. IEEE Journal of Selected Topics in Quantum Electronics 2009;15:563-71.

[62] Lester LF, Naderi NA, Grillot F, Raghunathan R, Kovanis V. Strong optical injection and the differential gain in a quantum dash laser. Optics Express 2014;22:7222-8.

[63] Pochet M, Naderi N, Terry N, Kovanis V, Lester L. Dynamic behavior of an injectionlocked quantum-dash Fabry-Perot laser at zero-detuning. Optics Express 2009;17: 20623-30.

[64] Pochet MC, Naderi NA, Kovanis V, Lester LF. Modeling the dynamic response of an optically-injected nanostructure diode laser. IEEE Journal of Quantum Electronics 2011;47:827-33. 
[65] Azouigui S, Dagens B, Lelarge F, Provost J, Accard A, Grillot F, et al. Tolerance to optical feedback of $10 \mathrm{gb} / \mathrm{s}$ quantum-dash-based lasers emitting at $1.51 \mu \mathrm{m}$. IEEE Photonics Technology Letters 2007;19:1181-3.

[66] Azouigui S, Dagens B, Lelarge F, Accard A, Make D, Le Gouezigou O, et al. Systematic investigation of InAs/InP quantum-dash based lasers under external optical feedback. Applied Physics Letters 2008;92:201106-201106-3.

[67] Azouigui S, Dagens B, Lelarge F, Provost J, Make D, Le Gouezigou O, et al. Optical feedback tolerance of quantum-dot-and quantum-dash-based semiconductor lasers operating at $1.55 \mathrm{~m}$. IEEE Journal of Selected Topics in Quantum Electronics 2009; 15:764-73.

[68] Grillot F, Naderi NA, Pochet M, Lin C-Y, Lester LF. Variation of the feedback sensitivity in a $1.55 \mu \mathrm{m}$ InAs/InP quantum-dash Fabry-Perot semiconductor laser. Applied Physics Letters 2008;93:191108-191108-3.

[69] Grillot F, Naderi NA, Pochet M, Lin C-Y, Besnard P, Lester LF. Tuning of the critical feedback level in 1.55- $\mu \mathrm{m}$ quantum dash semiconductor laser diodes. IET Optoelectronics 2009;3:242-7.

[70] Sadeev T, Huang H, Shires K, Arsenijević D, Grillot F, Bimberg D. Non-linear and dynamic properties of MOVPE-grown InAs/InP quantum-dot and quantum-dash Fabry-Perot lasers. In: 2015 IEEE Photonics conference (IPC), Reston, VA; 2015. p. $607-8$.

[71] Gosset C, Merghem K, Martinez A, Moreau G, Patriarche G, Aubin G, et al. Subpicosecond pulse generation at $134 \mathrm{GHz}$ using a quantum-dash-based Fabry-Perot laser emitting at $1.56 \mu \mathrm{m}$. Applied Physics Letters 2006;88:241105-241105-3.

[72] Dontabactouny M, Rosenberg C, Semenova E, Larsson D, Yvind K, Piron R, et al. $10-\mathrm{GHz} 1.59-\mu \mathrm{m}$ quantum dash passively mode-locked two-section lasers. In: SPIE photonics Europe; 2010. 77201A-77201A-10.

[73] Rosales R, Merghem K, Martinez A, Akrout A, Tourrenc J-P, Accard A, et al. InAs/InP quantum-dot passively mode-locked lasers for $1.55-\mu \mathrm{m}$ applications. IEEE Journal of Selected Topics in Quantum Electronics 2011;17:1292-301.

[74] Rosales R, Merghem K, Martinez A, Accard A, Lelarge F, Ramdane A. High repetition rate two-section InAs/InP quantum-dash passively mode locked lasers. In: IPRM 2011; 2011.

[75] Rosales R, Merghem K, Martinez A, Accard A, Lelarge F, Ramdane A. Two-section InAs/InP quantum-dash passively mode locked lasers. In: CLEO: science and innovations; 2011. CThG2.

[76] Asghar H, Wei W, Kumar P, Sooudi E, McInerney JG. Stabilization of self-modelocked quantum dash lasers by symmetric dual-loop optical feedback. Optics Express 2018;26:4581-92.

[77] Asghar H, Wei W, Kumar P, Sooudi E, Mcinerney JG. Narrow RF linewidth and low timing jitter performance of self-mode-locked quantum dash laser on full delay phase subject to feedback ratio controlled symmetric dual-loop configuration. https://arxiv. org/abs/1708.06612.

[78] Shen A, Gosset C, Renaudier J, Duan G, Oudar J, Lelarge F, et al. Ultra-narrow modebeating spectral line-width of a passively mode-locked quantum dot Fabry-Perot laser diode. In: Optical communications, 2006. ECOC 2006. European conference on; 2006. p. $1-2$. 
[79] Shen A, Provost J-G, Akrout A, Rousseau B, Lelarge F, Legouezigou O, et al. Low confinement factor quantum dash (QD) mode-locked Fabry-Perot (FP) laser diode for tunable pulse generation. In: Optical fiber communication conference. OThK1; 2008.

[80] Gosset C, Merghem K, Martinez A, Moreau G, Patriarche G, Aubin G, et al. Subpicosecond pulse generation at $134 \mathrm{GHz}$ and low radiofrequency spectral linewidth in quantum dash-based Fabry-Perot lasers emitting at $1.5 \mu \mathrm{m}$. Electronics Letters 2006;42:91-2.

[81] Akrout A, Shen A, Enard A, Duan G-H, Lelarge F, Ramdane A. Low phase noise alloptical oscillator using quantum dash modelocked laser. Electronics Letters 2010;46: 73-4.

[82] Latkowski S, Maldonado-Basilio RN, Landais P. Sub-picosecond pulse generation by 40-GHz passively mode-locked quantum-dash 1-mm-long Fabry-PÚrot laser diode. Optics Express 2009;17:19166-72.

[83] Maldonado-Basilio R, Latkowski S, Landais P. 720-fs pulse generation with $40 \mathrm{GHz}$ passively-mode locked quantum-dash Fabry-Perot laser. In: Optical communication, 2009. ECOC '09. 35th European conference on; 2009. p. 1-2.

[84] Maldonado-Basilio R, Parra-Cetina J, Latkowski S, Landais P. Timing-jitter, optical, and mode-beating linewidths analysis on subpicosecond optical pulses generated by a quantum-dash passively mode-locked semiconductor laser. Optics Letters 2010;35: 1184-6.

[85] Maldonado-Basilio R, Latkowski S, Surre F, Landais P. Linewidth analysis of 40-GHz passively mode-locked multi-mode semiconductor lasers. Optics Communications 2010;283:299-303.

[86] Latkowski S, Maldonado-Basilio R, Landais P. Short pulse generation with $40 \mathrm{GHz}$ passively-mode locked Q-dashed Fabry-Pérot laser. In: 11th international conference on transparent optical networks, 2009. ICTON '09; 2009. p. 1-4.

[87] Merghem K, Akrout A, Martinez A, Aubin G, Ramdane A, Lelarge F, et al. Pulse generation at $346 \mathrm{GHz}$ using a passively mode locked quantum-dash-based laser at $1.55 \mu \mathrm{m}$. Applied Physics Letters 2009;94.

[88] Merghem K, Calò C, Panapakkam V, Martinez A, Lelarge F, Ramdane A. Long-term frequency stabilization of $10-\mathrm{GHz}$ quantum-dash passively mode-locked lasers. IEEE Journal of Selected Topics in Quantum Electronics 2015;21(6):46-52.

[89] Calò C, Schmeckebier H, Merghem K, Rosales R, Lelarge F, Martinez A, et al. Frequency resolved optical gating characterization of sub-ps pulses from single-section InAs/InP quantum dash based mode-locked lasers. Optics Express 2014;22:1742-8.

[90] Calo C, Schmeckebier H, Merghem K, Rosales R, Lelarge F, Martinez A, et al. Frequency-resolved optical gating measurements of sub-ps pulses from InAs/InP quantum dash based mode-locked lasers. In: Indium phosphide and related materials (IPRM), 2013 international conference; 2013. p. 1-2.

[91] Sooudi E, de Dios C, McInerney JG, Huyet H, Lelarge L, Merghem K, et al. A novel scheme for two-level stabilization of semiconductor mode-locked lasers using simultaneous optical injection and optical feedback. IEEE Journal of Selected Topics in Quantum Electronics 2013;19:1101208-11.

[92] Wei W, Asghar H, Kumar P, Marah D, McInerney J. Sub-kHz RF linewidth of quantum-dash mode-locked laser by self-injection from symmetric dual-loop feedback and fiber delay. In: Conference on lasers and electro-optics. OSA Technical Digest; 2016. 
[93] Akrout A, Shen A, Brenot R, Dijk FV, Legouezigou O, Pommereau F, et al. Separate error-free transmission of eight channels at $10 \mathrm{~Gb} / \mathrm{s}$ using comb generation in a quantum-dash-based mode-locked laser. IEEE Photonics Technology Letters 2009; 21(23):1746-8.

[94] Nguyen QT, Besnard P, Bramerie L, Shen A, Kazmierski C, Chanlou P, Duan GH, Simon JC. Bidirectional 2.5-Gb/s WDM-PON using FP-LDs wavelength-locked by a multiple-wavelength seeding source based on a mode-locked laser. IEEE Photonics Technology Letters 2010;22(11):733-5.

[95] Silva MCE, Bramerie L, Gay M, Lobo S, Joindot M, Simon JC. 4×170 Gbit/s DWDM/ OTDM transmission using only one quantum dash Fabry Perot mode-locked laser. In: 36th European conference and exhibition on optical communication; 2010. p. 1-3.

[96] M'Sallem YB, Le QT, Bramerie L, Nguyen QT, Borgne E, Besnard P, Shen A, et al. Quantum-dash mode-locked laser as a source for 56-Gb/s DQPSK modulation in WDM multicast applications. IEEE Photonics Technology Letters 2011;23(7):453-5.

[97] Gay M, O'Hare A, Bramerie L, Hao Z, Fresnel S, Peucheret C, Besnard P, Joshi S, Barbet $\mathrm{S}$, Lelarge F. Single quantum dash mode-locked laser as a comb-generator in four-channel $112 \mathrm{Gbit} / \mathrm{s}$ WDM transmission. In: OFC 2014; 2014. p. 1-3.

[98] Pfeifle J, Watts R, Shkarban I, Wolf S, Vujicic V, Landais P, Chimot N, et al. Simultaneous phase noise reduction of $30 \mathrm{comb}$ lines from a quantum-dash mode-locked laser diode enabling coherent Tbit/s data transmission. In: 2015 optical fiber communications conference and exhibition (OFC); 2015. p. 1-3.

[99] Pfeifle J, Shkarban I, Wolf S, Kemal JN, Weimann C, Hartmann W, Chimot N, et al. Coherent Terabit communications using a quantum-dash mode-locked laser and selfhomodyne detection. In: 2015 optical fiber communications conference and exhibition (OFC); 2015. p. 1-3.

[100] Vujicic V, Calò C, Watts R, Lelarge F, Browning C, Merghem K, Martinez A, Ramdane A, Barry LP. Quantum dash passively mode-locked lasers for Tbit/s data interconnects. In: 2015 optical fiber communications conference and exhibition (OFC); 2015. p. 1-3.

[101] Vujicic V, Calò C, Watts R, Lelarge F, Browning C, Merghem K, Martinez A, Ramdane A, Barry LP. Quantum dash mode-locked lasers for data centre applications. IEEE Journal of Selected Topics in Quantum Electronics November 2015;21(6):53-60.

[102] Kemal JN, Marin-Palomo P, Merghem K, Aubin G, Calo C, Brenot R, Lelarge F, et al. 32QAM WDM transmission using a quantum-dash passively mode-locked laser with resonant feedback. In: 2017 optical fiber communications conference and exhibition (OFC); 2017. p. 1-3.

[103] Rosales R, Charbonnier B, Merghem K, Van Dijk F, Lelarge F, Martinez A, Ramdane A. InAs/InP quantum dash based mode locked lasers for $60 \mathrm{GHz}$ radio over fiber applications. In: 2012 international conference on indium phosphide and related materials; 2012. p. 185-7.

[104] Khan MTA, Alkhazraji E, Ragheb AM, Fathallah H, Alshebeili S, Khan MZM. 100 $\mathrm{Gb} / \mathrm{s}$ single channel transmission using injection-locked $1621 \mathrm{~nm}$ quantum-dash laser. IEEE Photonics Technology Letters 2017;29(6):543-6.

[105] Khan MTA, Shemis MA, Ragheb A, Esmail MA, Fathallah H, Alshebieli S, Khan MZM. 4 m/100 Gb/s optical wireless communication based on far L-band injection locked quantum-dash laser. IEEE Photonics Journal 2017;9(2):1-7. 


\section{CHAPTER 5 InAs/InP quantum-dash lasers}

[106] Shemis MA, Ragheb AM, Khan MTA, Fathallah HA, Alshebeili S, Qureshi KK, Khan MZM. L-band quantum-dash self-injection locked multiwavelength laser source for future WDM access networks. IEEE Photonics Journal 2017;9(5):1-7.

[107] Shemis MA, Ragheb AM, Alkhazraji E, Esmail MA, Fathallah H, Alshebeili S, Alshebeili S, Khan MZM. Self-seeded quantum-dash laser based $5 \mathrm{~m}-128 \mathrm{~Gb} / \mathrm{s}$ indoor free-space optical communication. Chinese Optics Letters 2017;15(10):100604. 